\title{
Continuity vs. the Crowd-Tradeoffs Between Continuous and Intermittent Citizen Hydrology Streamflow Observations
}

\author{
Jeffrey C. Davids $\mathbb{i}^{1,2} \cdot$ Nick van de Giesen ${ }^{1} \cdot$ Martine Rutten $^{1}$
}

Received: 24 September 2016 / Accepted: 8 April 2017 / Published online: 25 April 2017

(C) The Author(s) 2017. This article is an open access publication

\begin{abstract}
Hydrologic data has traditionally been collected with permanent installations of sophisticated and accurate but expensive monitoring equipment at limited numbers of sites. Consequently, observation frequency and costs are high, but spatial coverage of the data is limited. Citizen Hydrology can possibly overcome these challenges by leveraging easily scaled mobile technology and local residents to collect hydrologic data at many sites. However, understanding of how decreased observational frequency impacts the accuracy of key streamflow statistics such as minimum flow, maximum flow, and runoff is limited. To evaluate this impact, we randomly selected 50 active United States Geological Survey streamflow gauges in California. We used 7 years of historical 15-min flow data from 2008 to 2014 to develop minimum flow, maximum flow, and runoff values for each gauge. To mimic lower frequency Citizen Hydrology observations, we developed a bootstrap randomized subsampling with replacement procedure. We calculated the same statistics, and their respective distributions, from 50 subsample iterations with four different
\end{abstract}

Electronic supplementary material The online version of this article (doi:10.1007/s00267-017-0872-x) contains supplementary material, which is available to authorized users.

Jeffrey C. Davids

J.C.Davids@tudelft.nl

Nick van de Giesen

N.C.vandeGiesen@tudelft.nl

Martine Rutten

M.M.Rutten@tudelft.nl

1 Delft University of Technology, TU Delft Building 23, Stevinweg 1, Delft 2628 CN, Netherlands

2 SmartPhones4Water, 3881 Benatar Way, Suite G, Chico, CA 95928, USA subsampling frequencies ranging from daily to monthly. Minimum flows were estimated within $10 \%$ for half of the subsample iterations at 39 (daily) and 23 (monthly) of the 50 sites. However, maximum flows were estimated within $10 \%$ at only 7 (daily) and 0 (monthly) sites. Runoff volumes were estimated within $10 \%$ for half of the iterations at 44 (daily) and 12 (monthly) sites. Watershed flashiness most strongly impacted accuracy of minimum flow, maximum flow, and runoff estimates from subsampled data. Depending on the questions being asked, lower frequency Citizen Hydrology observations can provide useful hydrologic information.

Keywords SmartPhones4Water $\cdot$ Citizen science $\cdot$ Citizen hydrology $\cdot$ Subsampling $\cdot$ Streamflow $\cdot$ Nepal

\section{Background and Introduction}

Natural resource managers rely on timely and accurate data to make management decisions. Though water resources for human purposes is one of the most fundamental ecosystem services (Buytaert et al. 2014), fundamental data required to adequately manage water resources is often lacking both spatially and temporally (Gleick 1998; Hannah et al. 2011; Shrestha et al. 2012; and others). Remarkably, despite the multiple benefits of long term hydrologic records, the amount of river flow data being collected is actually declining in many parts of the world, especially in Africa, Latin America, Asia, and even North America (Mishra and Coulibaly 2009; Van de Giesen et al. 2014). The factors leading to this decline are diverse, but include a lack of understanding of the importance of long-term streamflow data, and persistent funding challenges (Pearson 1998). This lack of information makes it difficult to know how our 
water systems are changing over time and space due to natural or human activities, and to decide what management actions should be taken to either avoid or mitigate undesirable conditions in the present and future. In addition to remotely sensed stream stage and flow measurement techniques (Hirsch and Costa 2004; currently applicable to large rivers only), Citizen science appears to be a promising methodology for filling these data gaps (Sanz et al. 2014; Fienen and Lowry 2012).

Citizen Science is the process of involving citizens in the scientific process as researchers (Kruger and Shannon 2000). Citizen Science can include community based monitoring (Whitelaw et al. 2003) and/or community-based management (Keough and Blahna 2006). Citizen Science is on the rise in the USA (Whitelaw et al. 2003), Canada (Savan et al. 2003), and many other areas around the world (Sultana and Abeyasekera 2008; Nagendra et al. 2005). New developments in sensing technologies, data processing and analysis techniques, and methods of knowledge communication are opening novel opportunities for Citizen Science (Buytaert et al. 2014). In particular, recent advances in mobile technologies make smartphones a perfect tool for Citizen Science. Global Positioning Systems (GPS) and high resolution camera technology embedded in smartphones can be leveraged to collect verifiable records in the field. Cellular networks and the internet can be used to transmit collected data to a central repository.

Conventional methods for collecting hydrologic data depend on fixed deployments of advanced, highly accurate, but costly monitoring equipment installed at limited numbers of monitoring locations (Turnipseed and Sauer 2010). Therefore, observational frequency and expenses are high, but spatial extent of the resulting data is limited. Achieving adequate maintenance of sophisticated equipment can be costly (Mazzoleni et al. 2015), and in developing countries often exceeds local technical and resource capacity. Experience has shown that permanently deployed monitoring equipment is susceptible to corrosion, vandalism, and theft (van Overloop et al. 2014).

Applying Citizen Science to hydrologic data collection (i.e., Citizen Hydrology) has the potential to overcome these limitations. Fienen and Lowry (2012) demonstrated that Citizen Hydrology water level measurements using text message-based reporting can have acceptable errors. Mazzoleni et al. (2015) showed that crowdsourced streamflow observations can be integrated into hydrological models to improve flood predictions, and found the accuracy of individual measurements impacted results more than the irregularities in observation assimilation. Rather than using expensive installations at a few points, Citizen Hydrology leverages mobile technology to gather data at many sites, in a manner that is highly scalable, enabling the production of significantly more data than an individual organization possibly could (O'Grady et al. 2016). One of the tradeoffs for increased spatial resolution, however, is reduced temporal resolution.

We were interested in how decreased observation frequency associated with Citizen Hydrology observations affects the ability to accurately characterize critical streamflow metrics (e.g., runoff). Based on our review of the literature using search terms of streamflow, citizen science/hydrology, subsampling, and sample frequency, we could not identify other previous works addressing this particular theme. While Moss and Tasker (1991) used subsampling to evaluate two different hydrological network design technologies in order to maximize regional stream gauge information with limited funding and monitoring period, their subsampling was based on selecting subsets of sites and site-years of data (the entire year) to develop regressions for ungauged basins. Thoreson et al. (1999) investigated the relationship between different sampling intervals and water volume calculations, but in the context of irrigation canal systems, where flows are artificially managed to meet irrigation water requirements. One possible explanation for why this theme has not been explored is that existing literature assumes traditional streamflow monitoring approaches will be used, whereby permanent water level or water velocity sensing devices are installed and used to collect samples every 15-min (if not more frequently). Perhaps, therefore, it is often implicitly assumed that high frequency data records will be available if one is interested in monitoring streamflow.

An immediate application of this research is to inform monitoring plans for a Citizen Hydrology campaign in Nepal called SmartPhones4Water-Nepal (S4W-Nepal). The initial objective of S4W-Nepal is to further constrain the water budget in the Kathmandu Valley using underutilized sources of information, including water level and streamflow data collected by Citizen Hydrologists. At streamflow monitoring locations, low-cost staff gauges will be installed, and water level data will be collected by local residents with smartphones using an open source Android data collection platform called Open Data Kit (ODK) Collect (Anokwa et al. 2009). Within ODK Collect, each water level observation will require the Citizen Hydrologist to enter the water level reading, save the current date, time, GPS coordinates, and take a photograph of the observation. The data will be automatically transmitted to a centralized Google Cloud database via ODK Aggregate. Stage-discharge curves for the selected sites will be developed from monthly to bimonthly observations of discharge with a SonTek FlowTracker Acoustic Doppler Velocimeter performed by local BSc and MSc science and engineering students. Additional research is underway to explore the precision and accuracy of Citizen Hydrologist water level and discharge measurements. In addition to the various technical challenges, onsite 
training, frequent communication, and effective incentivization must also play a central role for the campaign to be successful and sustainable.

The goal of this paper is to evaluate the impacts of decreased observational frequency, which is a primary tradeoff of Citizen Hydrology observations, on estimates of minimum flow, maximum flow, and runoff. We attempt to meet this goal by performing a subsampling analysis on 7 years of data from 50 randomly selected United States Geological Survey (USGS) stream gauges in California. The three hypotheses we further evaluate are: (1) decreased observational frequency will negatively impact accuracy of flow and runoff estimates, (2) the nature of this impact will differ depending on the parameter in question, and (3) there will be correlations between accuracy of flow and runoff estimates and latitude, watershed area, Richards-Baker Flashiness Index (R-B Index), and storage ratio (see section Correlation analysis for details). The following analysis assumed (1) subsampled water level observations were as precise and accurate as continuous USGS records and (2) an equally accurate stage-discharge curve was available for converting water levels to flows. While not addressed in this paper, these simplifying assumptions highlight two important areas where further research is required if Citizen Hydrology is to help fill the globally widening hydrologic data gap.

\section{Materials and Methods}

\section{Streamflow Data}

We compiled an inventory of the 403 streamflow gauging stations (gauges or sites) in the state of California operated and maintained by the USGS with 15-min water level and flow data from January 1st 2008 to December 31st 2014. From this inventory, 50 streamflow gauges were randomly selected. For these 50 gauges, we compiled 15-min records and station metadata including the name, location, and elevation of the gauging station. Figure 1 shows the location of the 50 gauging stations labeled by the USGS Station ID or SiteID. Basic information about the 50 gauges is provided as supplemental material to this paper.

\section{Subsampling Procedure}

To mimic Citizen Hydrology observations at a lower observation frequency than the continuous record, we developed a bootstrap randomized subsampling with replacement procedure to generate randomized subsample datasets from each gauge record. The subsample datasets were randomly selected from the continuous record at average subsample intervals of once a day, every three days, weekly, and monthly. The subsampling procedure was similar to that used by Jones et al. (2012) to assess the influence of sampling frequency on total phosphorus and total suspended solid loads. The subsampling algorithms detailed in Eqs 1-4 were implemented to develop multiple subsample iterations via sampling with replacement. The subsampling procedure was coded in Python (Python v2.7 2016), and is available at GitHub at https://github.com/jcda vids/CAFlowSubsample. This procedure was then repeated for 50 iterations to provide additional information about the distributions of the resulting statistics. The following is a description of the subsampling process.

Suppose the original 15-min time series data set is given by the formula

$\boldsymbol{q}_{y}=\left[q_{y}(1), q_{y}(2), \ldots q_{y}(r)\right]$,

where $\boldsymbol{q}_{\boldsymbol{y}}$ is a vector (i.e., one dimensional matrix) containing records of flow rate for gauging station $y$ from records 1 to $r ; r$ is the total number of records in the 15-min time series for each station. Now suppose that we randomly sample from $\boldsymbol{q}_{\boldsymbol{y}}$ based on the formula

$$
\boldsymbol{q} \boldsymbol{s s}_{\boldsymbol{y}, i}=\left[q_{y}\left(\operatorname{rss}_{y, i}[0]\right), q_{y}\left(\operatorname{rss}_{y, i}[1]\right), \ldots q_{y}\left(\operatorname{rss}_{y, i}[N]\right)\right],
$$

where $\boldsymbol{q} \boldsymbol{s} \boldsymbol{s}_{y, i}$ is the subsample flow vector containing all subsampled records for gauging station $y$ and iteration $i$. Because we require the subsample to be a random selection with on average even spacing between subsamples, we define the records that should be used for the subsamples used to develop $\boldsymbol{q} \boldsymbol{s \boldsymbol { s } _ { y , i }}$ with the formula

$$
\boldsymbol{r s s}_{y, i}=\left[\frac{S}{2}+n * S+\mathrm{RI}_{n}\right]_{n=0}^{N},
$$

where $\boldsymbol{r} \boldsymbol{s s}_{y, i}$ is the subsample record vector containing the randomly selected records used to develop the subsample flow vector $\boldsymbol{q} \boldsymbol{s} \boldsymbol{s}_{y, i} . S$ is the average subsample interval (an even integer) and $n$ is the subsample number ranging from 0 to $N$. The value of $N$ is given by the formula

$$
N=\operatorname{int}\left(\text { floor }\left(\frac{r}{S}\right)\right)-1 \text {. }
$$

The functions int() and floor() select the nearest integer below $r / S$. For example, if $r / S$ was 83.94, then the combined functions would return $83 . \mathrm{RI}_{n}$ is a random integer ranging from $-S / 2$ to $S / 2$. Offsetting $\frac{S}{2}+n * S$ by $\mathrm{RI}_{n}$ ensures that each subsample will be somewhere within the range of $S$ centered about $\frac{S}{2}+n * S$. In our case, $S$ was set to 96 (daily), 288 (three days), 672 (weekly), and 2922 (monthly). Per the minimum recommended number of bootstrap samples by Efron and Tibshirani (1993), 50 iterations (i) of $\boldsymbol{r} \boldsymbol{s} \boldsymbol{s}_{y, i}$ were developed for each gauging station $(y)$ to assess the resulting distributions for minimum flow, maximum flow, and runoff volume.

To summarize the subsampling process: first, we developed subsample record vectors using Eq. 3 for each gauging 
Fig. 1 Map of California showing 50 randomly selected USGS stream gauging sites. All major waterways in the state are shown in light blue. A location map of the West Coast of the U.S. is also shown on the top right. Subsampled hydrograph results shown in section Example subsampled hydrographs are for the Truckee River Near Farad (SiteID 10346000), which is the northern most site on the California-Nevada border

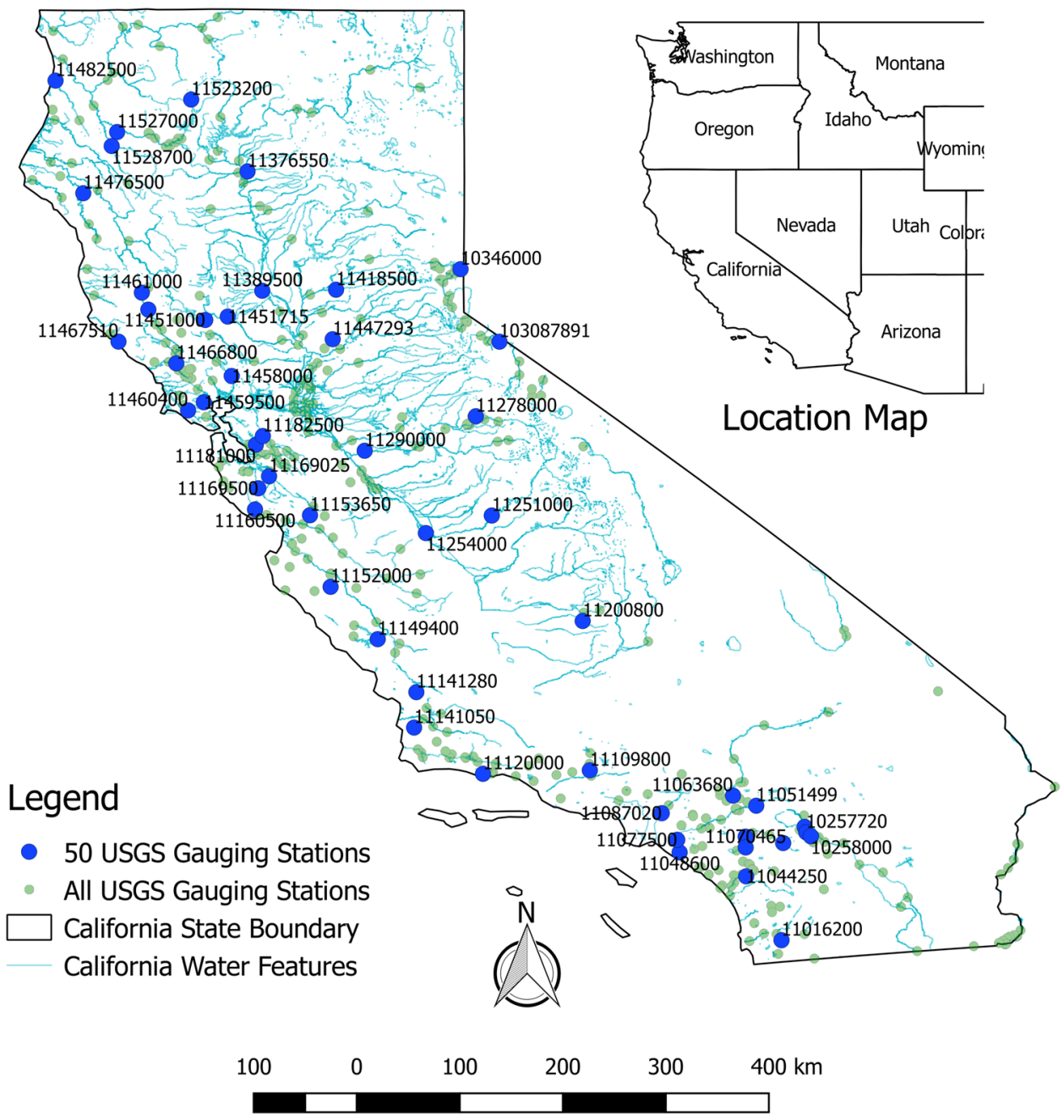

station and iteration, and second, we developed subsample flow vectors using Eq. 2. In total, we developed 2500 subsamples (i.e., $y$ sites times $i$ subsamples, or 50 times 50) for each of the four subsample intervals $\mathrm{S}$, for a total of 10,000 subsamples. The average size of each resulting subsample was 2571, 857, 367, and 84 records for daily, three day, weekly, and monthly subsampling intervals, respectively. A sample result of the subsampling procedure is presented in section Example subsampled hydrographs for the Truckee River near Farad (SiteID 10346000).

\section{Comparison Statistics}

We compiled the 50 original 15-min data sets and the 10,000 subsamples into Microsoft Access SQL databases. SQL queries were developed to compute normalized statistical comparisons (see section Flow ratios) for the 15-min records and subsampled data. In all cases, the flow ratios were aggregated over the entire 7 -year period (period) from the beginning of 2008 to the end of 2014. For purposes of comparison and normalization, the actual period minimum flow, maximum flow, and runoff volume for each station was determined from the 15-min data. As previously stated, each individual subsample observation was assumed to have the same flow measurement accuracy as the original 15-min observations.

\section{Flow ratios}

A normalized minimum flow ratio between minimum flow obtained from subsampled data for each gauging station $(y)$ and iteration (i) (i.e., $\operatorname{Qmin}_{y, i}$ ) and actual minimum flow from 15-min record (i.e., $\operatorname{Qmin}_{a}$ ) expressed as a fraction (i.e., Q $\min _{a} / \mathrm{Qmin}_{y, i}$ ) was used for comparison purposes. The actual minimum is placed in the numerator so that the minimum flow ratio ranges from 0 to 1 .

A normalized maximum flow ratio between maximum flow obtained from subsampled data for each gauging station $(y)$ and iteration ( $i$ ) (i.e., $\operatorname{Qmax}_{y, i}$ ) and actual maximum flow from 15-min record (i.e., $\operatorname{Qmax}_{a}$ ) expressed as a 
fraction (i.e., $\mathrm{Qmax}_{y, i} / \mathrm{Qmax} a$ ) was used for comparison purposes. Maximum flow ratio ranges from 0 to 1 .

A normalized runoff ratio between runoff calculated from subsampled data for each gauging station $(y)$ and iteration (i) (i.e., $V_{y, i}$ ) and actual runoff from 15-min record (i.e., $V_{a}$ ) expressed as a fraction (i.e., $V_{y, i} / V_{a}$ ) was used for comparison purposes. Runoff ratio ranges from 0 to infinity.

In all cases, if the denominator was 0 , a value of 1 was returned. Ratios closer to 1 represent better agreement between subsampled data and the original 15-min records.

\section{Correlation analysis}

A correlation analysis was performed to assess relationships between minimum flow, maximum flow, and runoff ratios and the following variables: (1) latitude, (2) watershed area, (3) the R-B index, and (4) storage ratio. The first three variables were chosen to explore possible geographic, spatial scale, and temporal/magnitude-based dependencies, respectively. Storage ratio was selected because of the intuitive relationship between the "flattening" of the hydrograph discussed by Vörösmarty and Sahagian (2000) and the flow ratios being investigated. The results of the correlation analysis are presented in section Correlation analysis results. Note that there are mathematical dependencies between some variables; runoff ratio, R-B index, and storage ratio are each normalized by runoff (further discussed in section Correlation analysis results).

The R-B Index is a unitless value used to quantify the flashiness of a watershed (Baker et al. 2004). The R-B Index normalizes fluctuations in flow by the total flow over a given period, so that flashiness between watersheds can be compared. The entire 7-year study period was used for calculating the R-B Index.

Storage ratio is a unitless value calculated as the total usable reservoir water storage upstream of the gauging station divided by average annual runoff measured at the gauging station for the 7-year study period (Vörösmarty and Sahagian 2000). Usable reservoir water storage was calculated as the sum of the difference between maximum storage volume and dead pool volume for all reservoirs upstream of each gauging station. Storage potential of upstream soils, groundwater systems, and floodplains were not included in the storage ratio. The storage ratio attempts to normalize storage upstream of each gauging station, so that the impacts of reservoir storage can be quantitatively determined and compared among all gauging stations. Note that three storage ratios (SiteIDs 11051499, 11077500, and $11109800)$ are marked with an asterisk (*) in the supplemental materials. For these three sites, artificially imported water is stored in upstream reservoirs, so the amount of storage available is large compared to natural annual runoff.
These three sites are not used in correlation analyses involving storage ratio.

\section{Hypotheses, Visualization Methods, and Evaluation Criteria}

Table 1 provides a summary of the five visualization methods used in sections Flow ratio results and Correlation analysis results, organized by three hypotheses being evaluated. Criteria for evaluating each visualization method are provided in the right column.

The following are additional sub-hypotheses related to the third (3) hypothesis in Table 1.

- Increasing latitude will improve estimates of maximum flow and runoff, but will worsen estimates of minimum flow.

- Increasing watershed area will improve estimates of minimum flow, maximum flow, and runoff.

- Increasing R-B Index will improve estimates of minimum flow, but will worsen estimates of maximum flow and runoff.

- Increasing storage ratio will improve estimates of minimum flow, maximum flow, and runoff.

\section{Results}

\section{Example Subsampled Hydrographs}

The subsampling selections and resulting hydrographs for daily, three day, weekly, and monthly subsample intervals are shown on Fig. 2 for the Truckee River near Farad (SiteID 10346000) near the California-Nevada state border for May 2010. Shown on each of the graphs (a-d) are (1) the original 15-min hydrograph (dark blue), (2) the subsampled hydrograph resulting from iteration 1 (red), and (3) the bootstrap randomized subsamples with replacement for each of the 50 iterations (light blue dots). The hydrograph represents a typical spring runoff superimposed with spring precipitation events in the Sierra Nevada mountains. The shorter scale temporal dynamics of the 15-min hydrograph are progressively lost as the subsample frequency decreases from daily to monthly. For example, the daily subsampled hydrograph shown by the red trace in Fig. 2a follows the general trends of the 15-min hydrograph shown in blue. However, the monthly subsampled hydrograph shown by the red trace in Fig. 2d almost completely misses the peaks and troughs shown in the 15-min hydrograph.

Each hydrograph can be constructed by (1) selecting a horizontal gridline representing a subsample iteration, and then (2) moving vertically from each light blue dot on the selected subsample iteration gridline until the 15-min 
hydrograph is reached. The random distribution of the roughly $1500,500,200$, and 50 light blue dots, respectively, illustrates that the subsampling method described in section Subsampling procedure is providing good subsample randomization.

\section{Flow Ratio Results}

Table 2 provides a summary of the number of sites that had at least half of the iterations of subsampled flow ratios within \pm 10 and $\pm 20 \%$ of actual flow ratios for the four subsample intervals evaluated.

For minimum flow ratio with a daily subsample interval, 39 and 42 of the 50 sites had a $50 \%$ chance that subsampled minimum flows were within \pm 10 and $\pm 20 \%$ of the actual minimum, respectively. For the monthly subsample interval, 23 and 25 of the 50 sites had a $50 \%$ chance that subsampled minimum flows were within \pm 10 and $\pm 20 \%$ of the actual minimum, respectively.

For maximum flow ratio with a daily subsample interval, only seven of the 50 sites had subsampled maximum flow within \pm 10 and $\pm 20 \%$ of the actual maximum. None of the 50 sites had monthly subsampled maximum flows within $\pm 10 \%$, and only two were within $\pm 20 \%$ of actual maximum flows.

For runoff ratio with a daily subsample interval, 44 and 49 of the 50 sites had a $50 \%$ chance that subsampled minimum flows were within \pm 10 and $\pm 20 \%$ of the actual runoff, respectively. For the monthly subsample interval, 12 and 22 of the 50 sites had a $50 \%$ chance that subsampled runoff values were within \pm 10 and $\pm 20 \%$ of actual runoff, respectively.

\section{Minimum flow results}

Results for minimum flows are shown in Figs 3 and 4. The distribution of minimum flow ratios, shown as box plots in Fig. 3, moves progressively towards zero on the vertical axis as the subsample frequency decreases. Notice that the median (interface between light and dark red) minimum flow ratios moved progressively towards zero as the subsample frequency decreased. The closer the points are to 1 on the vertical axis, the better the subsampled data characterizes minimum flows.

A histogram of minimum flow ratios for daily, three day, weekly, and monthly subsample intervals (Fig. 4) shows non-normal distributions for all subsample intervals. The distributions for all subsample intervals were similar and were more heavily weighted towards the right, but increasingly less so as the subsample interval increased. Nearly $72 \%$ of the site-subsample pairs (site-subsamples) had a minimum flow ratio greater than or equal to 0.9 . 
Fig. 2 Example bootstrap randomized subsamples with replacement for each of the 50 iterations (light blue dots), original 15-min hydrograph (dark blue), and hydrograph from subsample iteration 1 (red) for the Truckee River near Farad. The horizontal axis displays time, in this case the month of May from 2010. The primary (left) vertical axis displays subsample iteration number (i), and the secondary (right) vertical axis displays flow rate. Each horizontal gridline represents a single subsample iteration from 1 to 50. Each light blue square on the horizontal gridlines represents a date time selected for the respective subsample iteration. The 30 subsamples that make up the hydrograph for iteration 1 shown as red triangles coincide horizontally, that is with respect to time, with the 30 light blue squares on the first horizontal gridline above the $x$-axis (i.e., subsample iteration number 1). The data shown are for a daily, $\mathbf{b}$ three day, $\mathbf{c}$ weekly, and $\mathbf{d}$ monthly subsample intervals

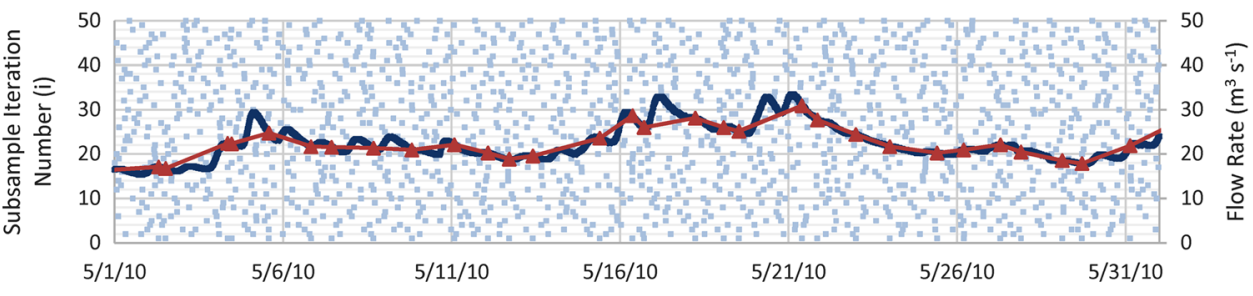

(a) " numlteration $\longrightarrow 15$ Minute Hydrograph $\rightarrow$ Daily Hydrograph (Iteration 1 )

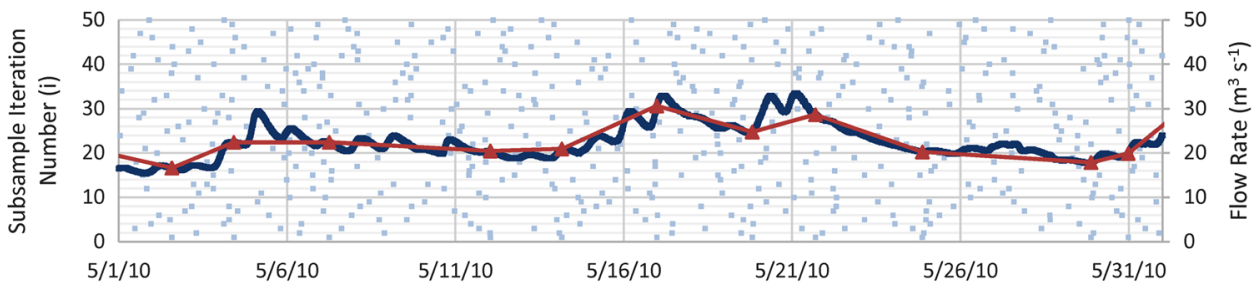

(b) " numlteration $\longrightarrow 15$ Minute Hydrograph $\rightarrow$ Three Day Hydrograph (Iteration 1)
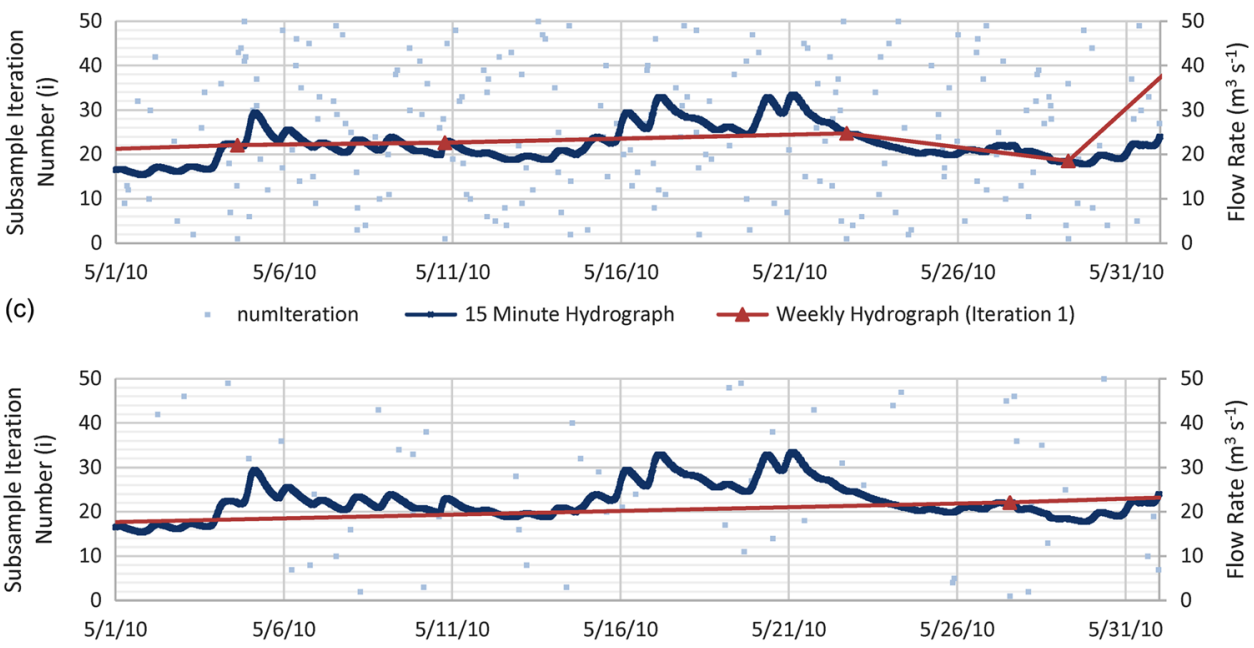

(d) = numlteration $\longrightarrow 15$ Minute Hydrograph $\rightarrow$ Monthly Hydrograph (Iteration 1)

\begin{tabular}{lllccc}
\hline Ratio & Subsample interval $(S)$ & Daily & Three days & Weekly & Monthly \\
\hline Min flow ratio & Number of sites within $\pm 10 \%$ & 39 & 35 & 31 & 23 \\
& Number of sites within $\pm 20 \%$ & 42 & 38 & 36 & 25 \\
\multirow{3}{*}{ Max flow ratio } & Number of sites within $\pm 10 \%$ & 7 & 5 & 3 & 0 \\
& Number of sites within $\pm 20 \%$ & 7 & 6 & 6 & 2 \\
\multirow{3}{*}{ Runoff ratio } & Number of sites within $\pm 10 \%$ & 44 & 39 & 27 & 12 \\
& Number of sites within $\pm 20 \%$ & 49 & 46 & 43 & 22
\end{tabular}

Table 2 Summary of the number of sites out of the 50 selected with at least half of the iterations (i.e., between the first and third quartile) with subsampled flow ratios within \pm 10 and $\pm 20 \%$ of actual flow ratios for the four subsample intervals evaluated

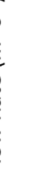

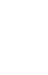


Daily $(S=96)$

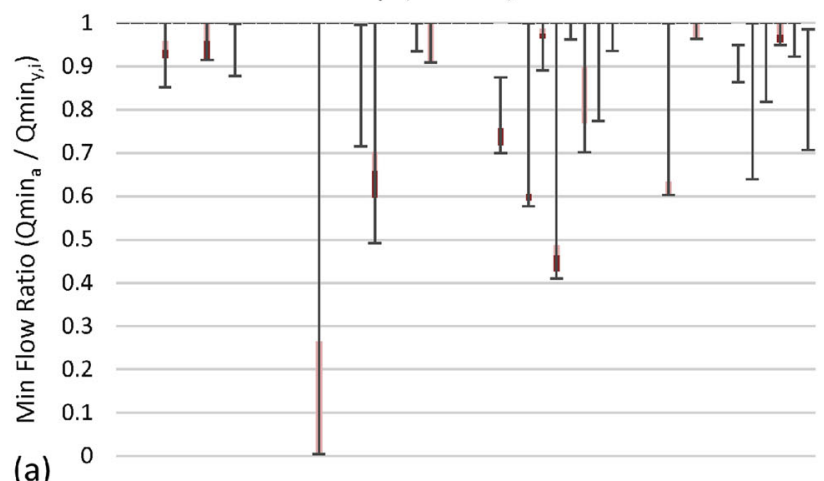

(a)

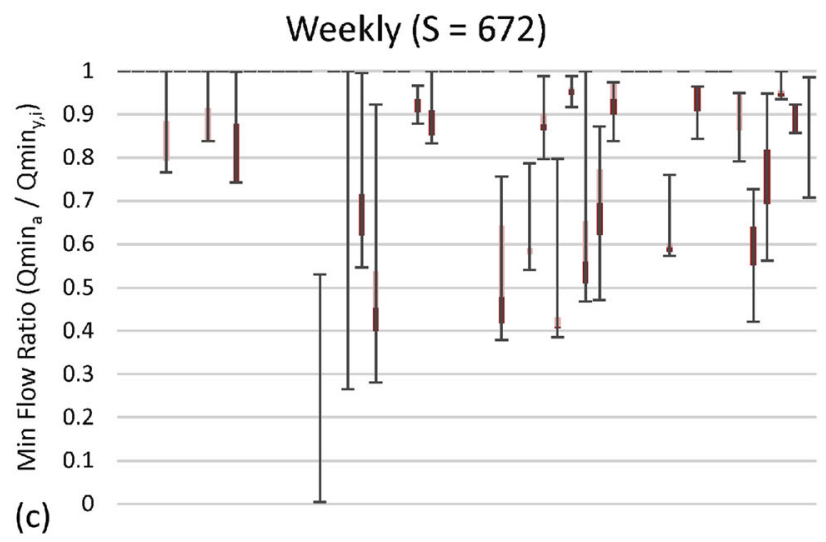

Fig. 3 Minimum flow ratio between actual minimum flow from the 15-min record (i.e., $\mathrm{Qmin}_{a}$ ) and minimum flow calculated from subsampled data for each gauging station $(y)$ and iteration (i) (i.e., $\mathrm{Qmin}_{y, i}$ ) and expressed as a fraction (i.e., $\mathrm{Qmin}_{a} / \mathrm{Q} \min _{y, i}$ ). All minimum flow ratios were calculated for the 7-year period from 2008 to 2014. Data for all four subsample intervals are shown starting from the top left. Each plot contains the median (Q2; interface between light and dark red), the 1st and 3rd quartiles (Q1 and Q3; bottom of dark red
Three Day $(S=288)$

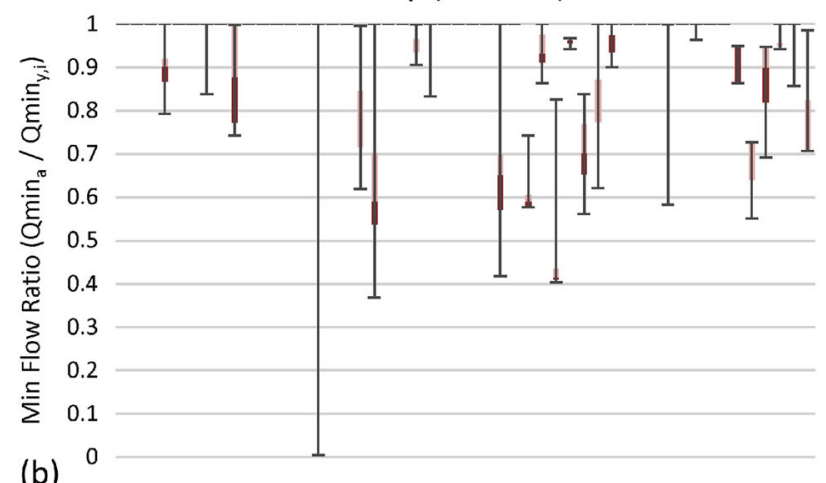

(b)

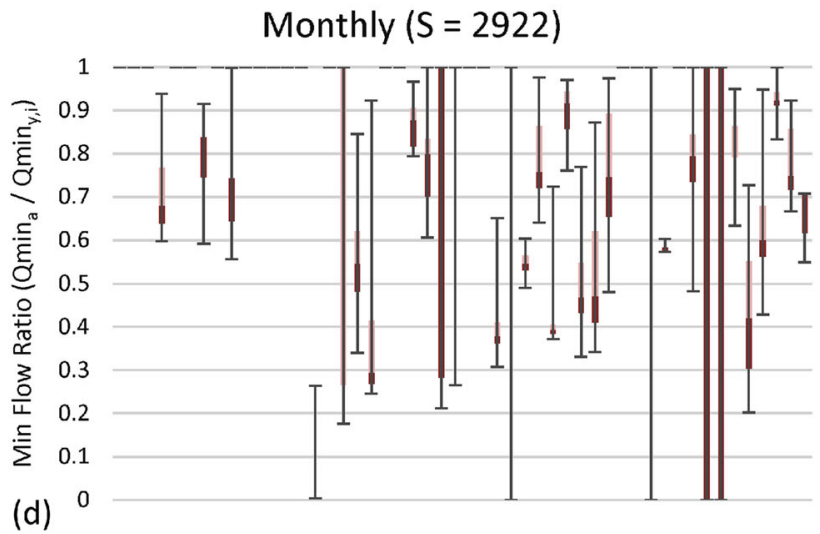

and top of light red respectively), and the minimum and maximum (negative and positive error bars, respectively). Note that sites with minimum, Q1, Q2, Q3, and maximum flow ratios equal to 1 are simply shown as a dash at the top of each graph. In cases where either Q1 and $\mathrm{Q} 2$, or Q2 and Q3 are coincident, no light or dark red rectangles are visible, respectively. Sites are sorted in ascending order by SiteID. The data shown are for a daily, b three day, $\mathbf{c}$ weekly, and $\mathbf{d}$ monthly subsample intervals
Fig. 4 Histogram and basic statistics of minimum flow ratios for all four subsample intervals

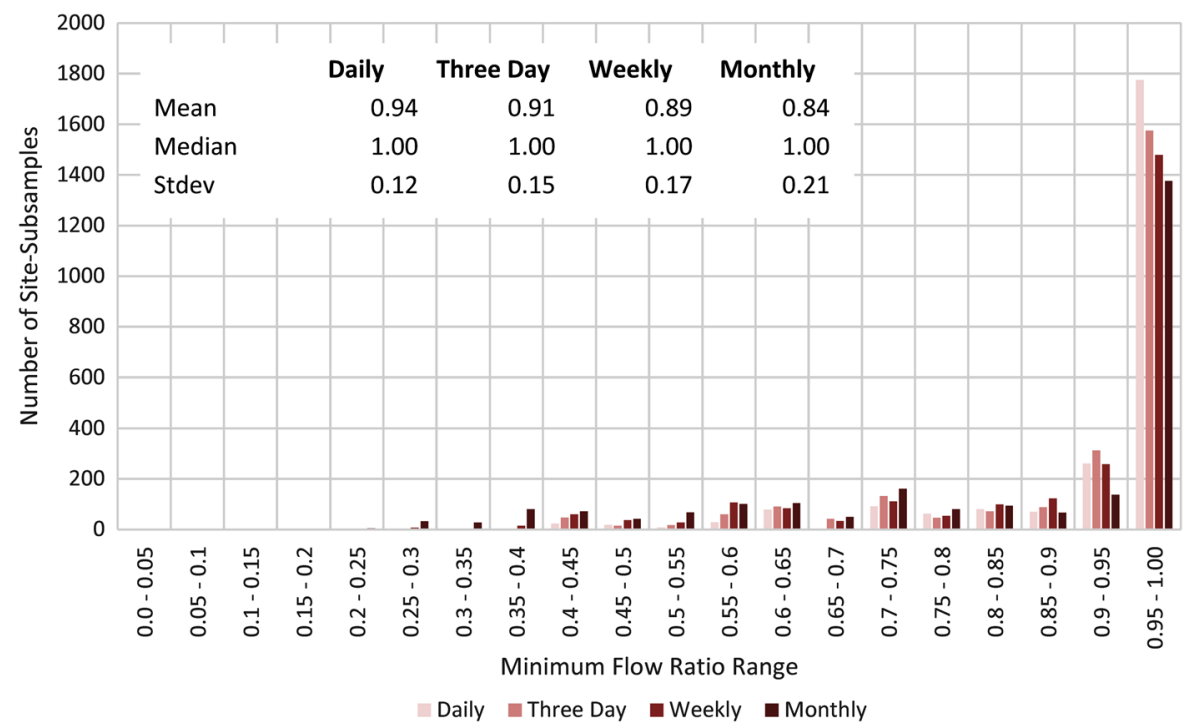




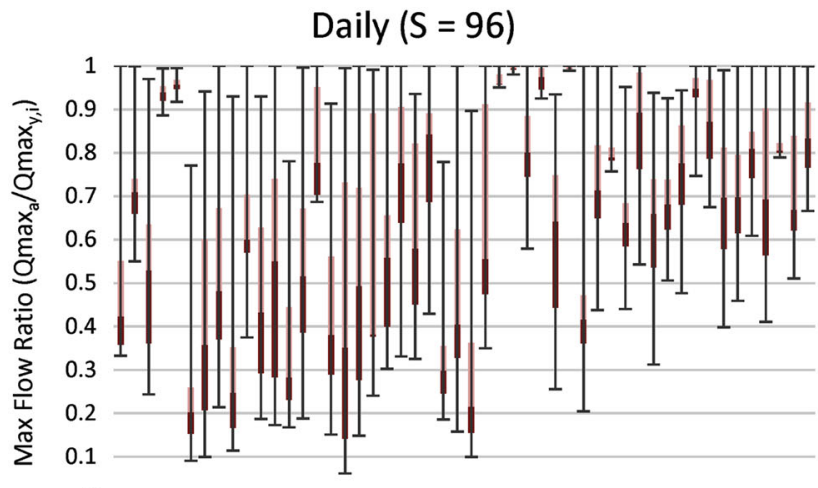

(a)

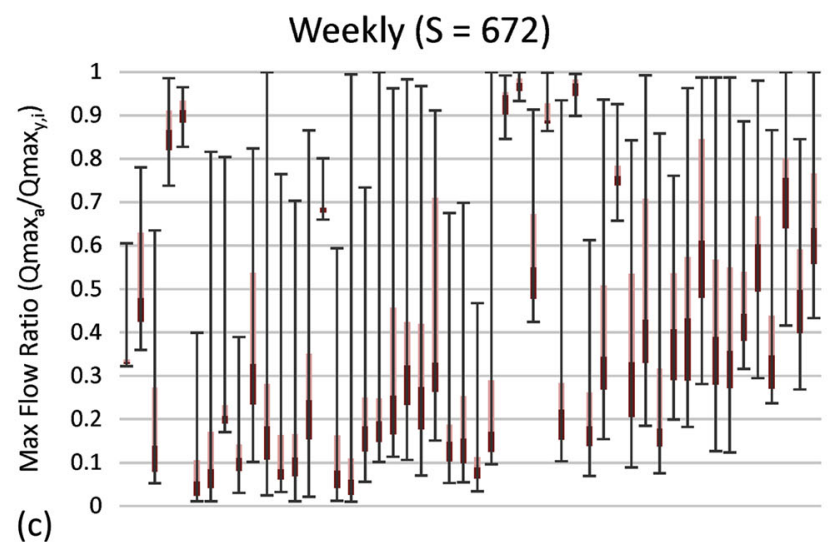

Fig. 5 Maximum flow ratio between maximum flow calculated from subsampled data for each gauging station $(y)$ and iteration (i) (i.e., $\operatorname{Qmax}_{y, i}$ ) and actual maximum flow from the 15-min record (i.e., $\mathrm{Qmax}_{a}$ ) expressed as a fraction (i.e., $\mathrm{Qmax}_{y, i} / \mathrm{Qmax}_{a}$ ). All maximum flow ratios were calculated for the 7-year period from 2008 to 2014. Data for all four subsample intervals are shown. Each plot contains the median $(\mathrm{Q} 2$; interface between light red and dark red $)$, the 1st and 3rd
Three Day $(S=288)$

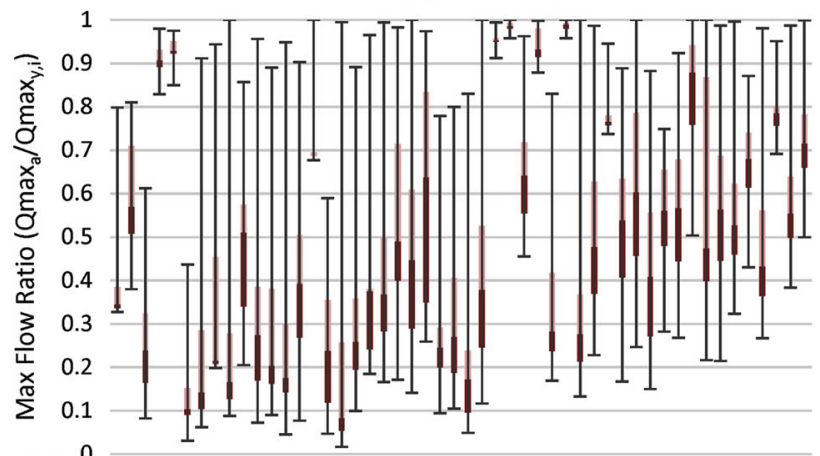

(b)

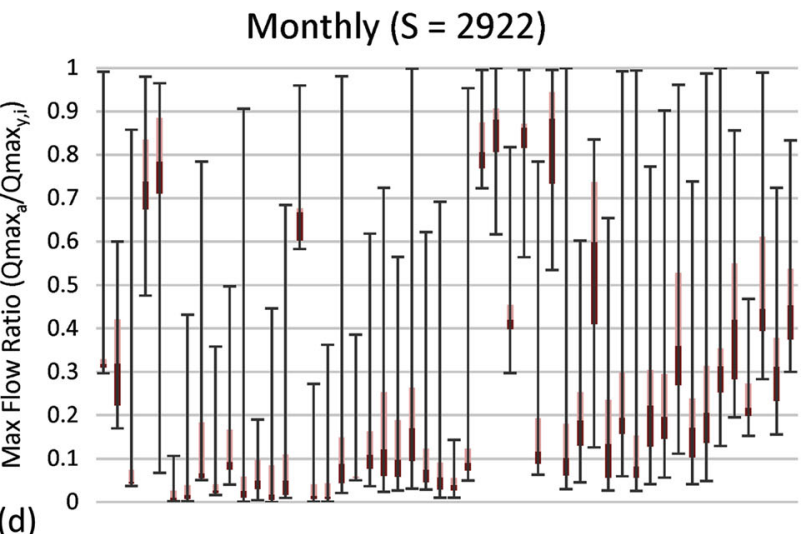

quartiles (Q1 and Q3; bottom of dark red and top of light red respectively), and the minimum and maximum (negative and positive error bars, respectively). In cases where either Q1 and Q2, or Q2 and Q3 are coincident, no light or dark red rectangles are visible, respectively. Sites are sorted in ascending order by SiteID. The data shown are for a daily, $\mathbf{b}$ three day, $\mathbf{c}$ weekly, and $\mathbf{d}$ monthly subsample intervals
Fig. 6 Histogram and basic statistics of maximum flow ratios for all four subsample intervals

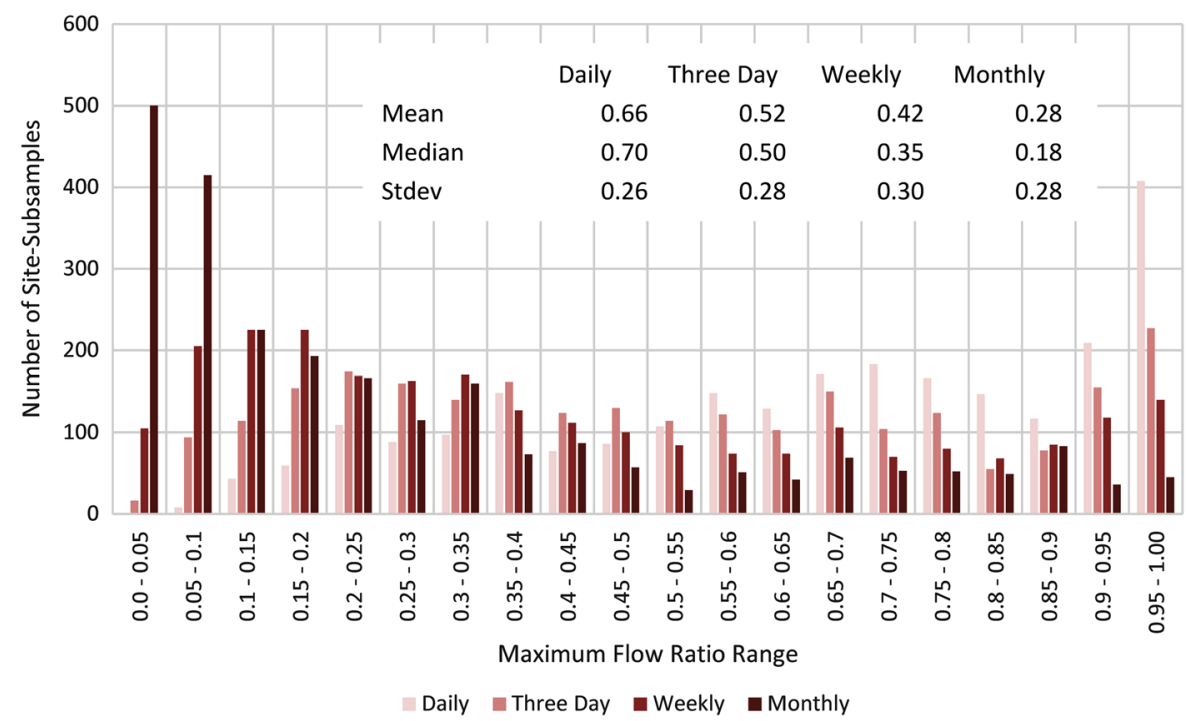


were non-normal. The daily subsample distribution was more heavily weighted to the right, with 0.9 to 0.95 and 0.95 to 1.00 containing the highest number of sitesubsamples $(n=617$ or roughly $25 \%)$. In contrast, the monthly subsample distribution was more heavily weighted to the left, with 0.0 to 0.05 , and 0.05 to 0.1 containing the highest number of site-subsamples $(n=915$ or roughly $37 \%)$.
Daily $(S=96)$

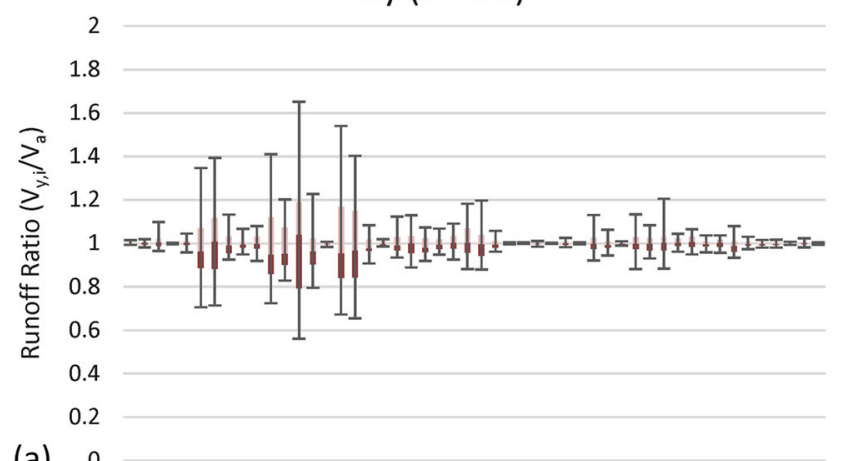

(a) 0

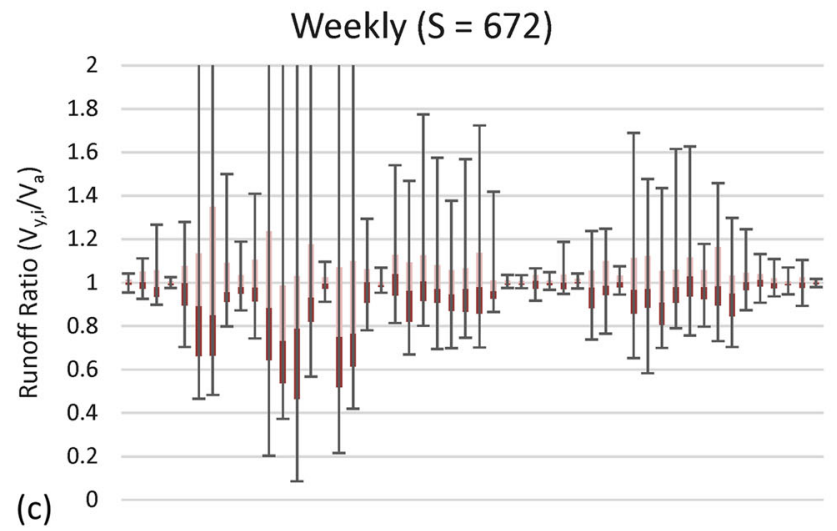

Fig. 7 Runoff ratio between runoff calculated from subsampled data for each gauging station $(y)$ and iteration $(i)$ (i.e., $\mathrm{V}_{y, i}$ ) and actual runoff from 15-min record (i.e., $\mathrm{V}_{a}$ ) expressed as a fraction (i.e., $\mathrm{V}_{y, i} / \mathrm{V}_{a}$ ). Both runoff values are calculated for the 7-year period from 2008 to 2014. Data for all four subsample intervals are shown. Each plot contains the median

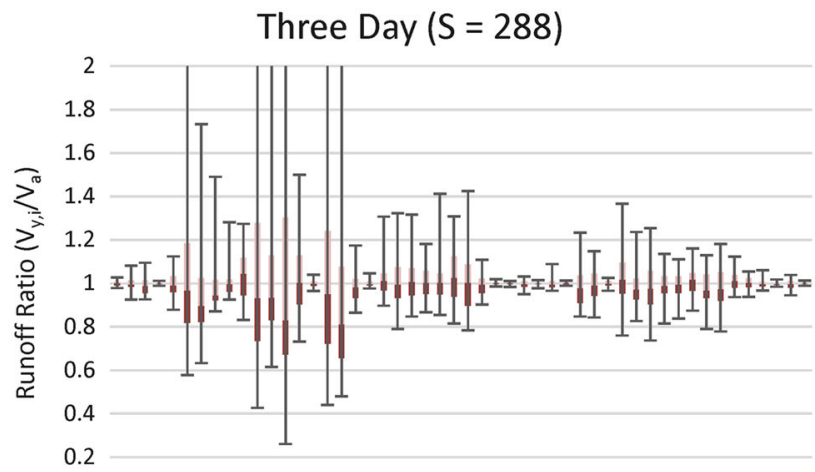

(b) 0

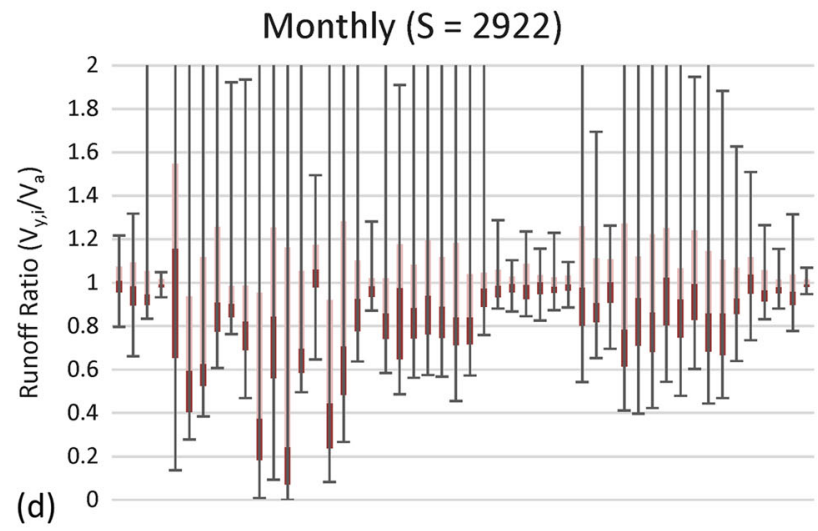

(Q2; interface between light and dark red), the 1st and 3rd quartiles (Q1 and Q3; bottom of dark red and top of light red, respectively), and the minimum and maximum (negative and positive error bars respectively). Sites are sorted in ascending order by SiteID. The data shown are for a daily, $\mathbf{b}$ three day, $\mathbf{c}$ weekly, and $\mathbf{d}$ monthly subsample intervals
Fig. 8 Histogram and basic statistics of runoff ratios for all four subsample intervals

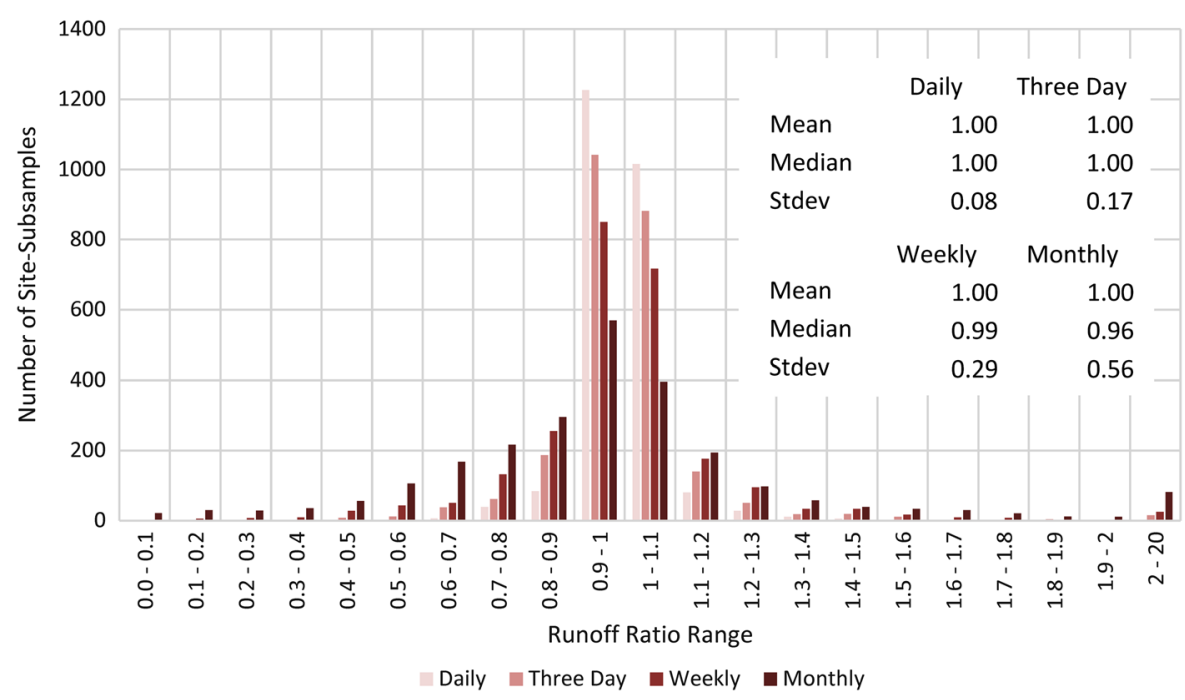




\section{Runoff results}

Results for the runoff (volume) are shown in Figs 7 and 8. Figure 7 shows box plots of runoff ratios. The vertical axis scale is locked from 0 to 2 , however, for subsample intervals greater than daily, some of the maximum runoff ratios (maximum error bars) were above 2 and are therefore not shown on the plot. The data move progressively farther from 1 as the subsample frequency decreases, indicating that runoff volume estimates became more uncertain as observation frequency decreased. The median values (interface between light and dark red) moved increasingly downwards from 1 as the subsample frequency decreased, representing an amplified negative bias in runoff estimates.
There was a systematic negative bias in the runoff estimates, as evidenced by the greater number of sites below 1 than above 1 for all subsample intervals. Runoff was underestimated for $54,54,55$, and $61 \%$ of site-subsamples for daily, three day, weekly, and monthly subsample intervals, respectively. This indicates that the negative bias was stronger as the subsample frequency decreased. This trend is also illustrated by the median being consistently below the 1 runoff ratio line in Fig. 8, especially as the subsample frequency decreased to weekly and monthly.

Figure 9 presents a geographic summary of the subsampling results for runoff. At each location there are four concentric and scaled circles. Daily, three day, weekly, and monthly subsample intervals are shown in blue, green,
Fig. 9 Map figure of 50 USGS stream gauges labeled with USGS Station ID. At each location, there are four concentric and scaled circles. The circles are scaled by maximum runoff error (i.e., maximum of the runoff ratio residuals) within the 1 st and 3rd quartiles from the 50 subsample iterations. Daily, three day, weekly, and monthly subsample intervals are shown in blue, green, yellow, and red, respectively

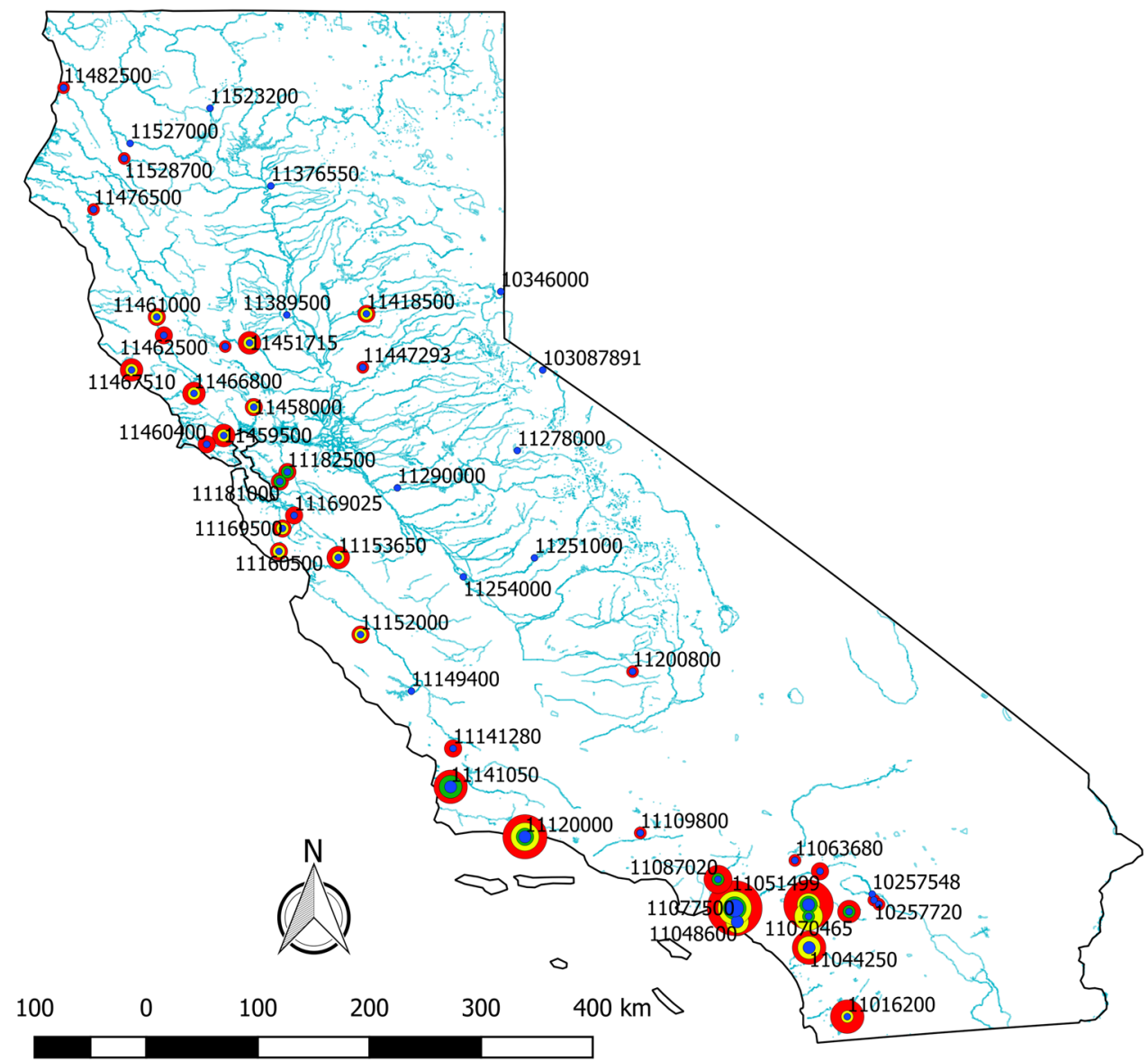

\section{Legend}

\begin{tabular}{|c|c|}
\hline \multicolumn{2}{|c|}{ Max Runoff Error (Q1 to Q3) } \\
\hline$\circ$ & $0.000-0.100$ \\
\hline 0 & $0.100-0.200$ \\
\hline 0 & $0.200-0.300$ \\
\hline 0 & $0.300-0.400$ \\
\hline
\end{tabular}




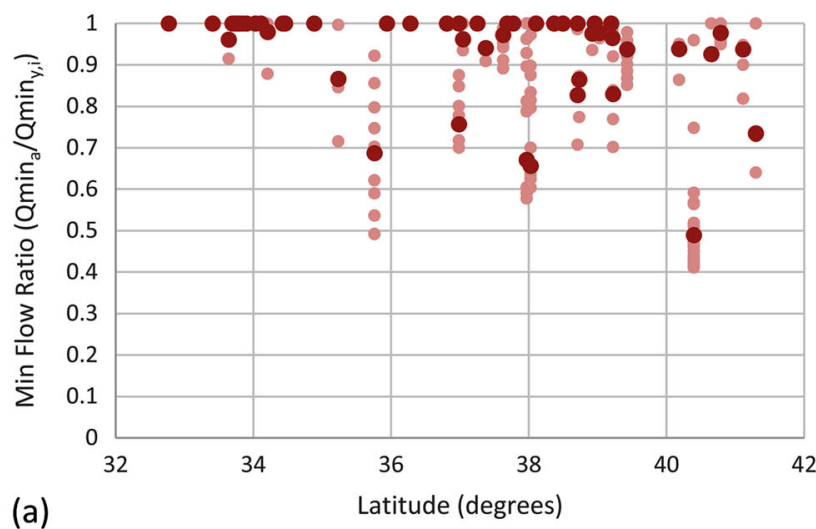

(a)

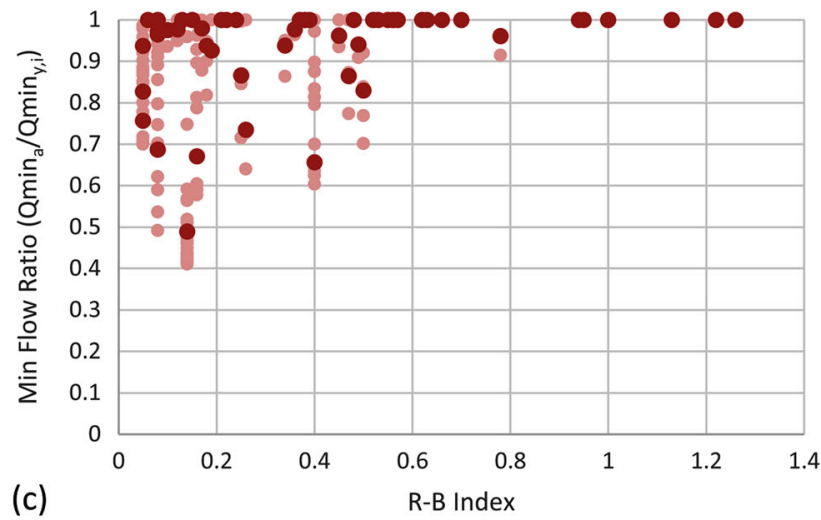

Fig. 10 Scatter plots of minimum flow ratio as a function of a Latitude (decimal degrees), b watershed area $\left(\mathrm{km}^{2}\right)$, c Richards-Baker flashiness index (R-B Index), and $\mathbf{d}$ storage ratio. Average data for all 50 sites shown in dark red; data for all 50 iterations shown in light red.

yellow, and red, respectively. The size of the circle corresponds to the maximum from all 50 iterations of the absolute value of the runoff ratio minus one for the 1 st and 3 rd quartiles. In other words, there is a $50 \%$ chance that a runoff estimate would be within the displayed fraction of the actual runoff. For example, daily and monthly subsamples for Atascadero Creek near Goleta (SiteID 11120000) have a 50\% chance of having runoff estimates within $16.8 \%$ (i.e., 0.168 ) and $76.4 \%$ (i.e., 0.764 ) of actual runoff, respectively. In general, watersheds in the San Francisco Bay Area (e.g., SiteIDs 11182500 and 11181000) and watersheds in Southern California (e.g., SiteIDs 11077500, 11070270, and 11070465) had the highest runoff ratio residuals for all subsample intervals. These watersheds also tend to exhibit greater flashiness, as indicated by higher R-B Index values.

\section{Correlation Analysis Results}

Figures 10 to 12 show scatter plots between minimum flow, maximum flow, and runoff ratios, and (a) latitude, (b) watershed area, (c) R-B Index, and (d) storage ratio, respectively. Data are shown for daily sampling frequencies
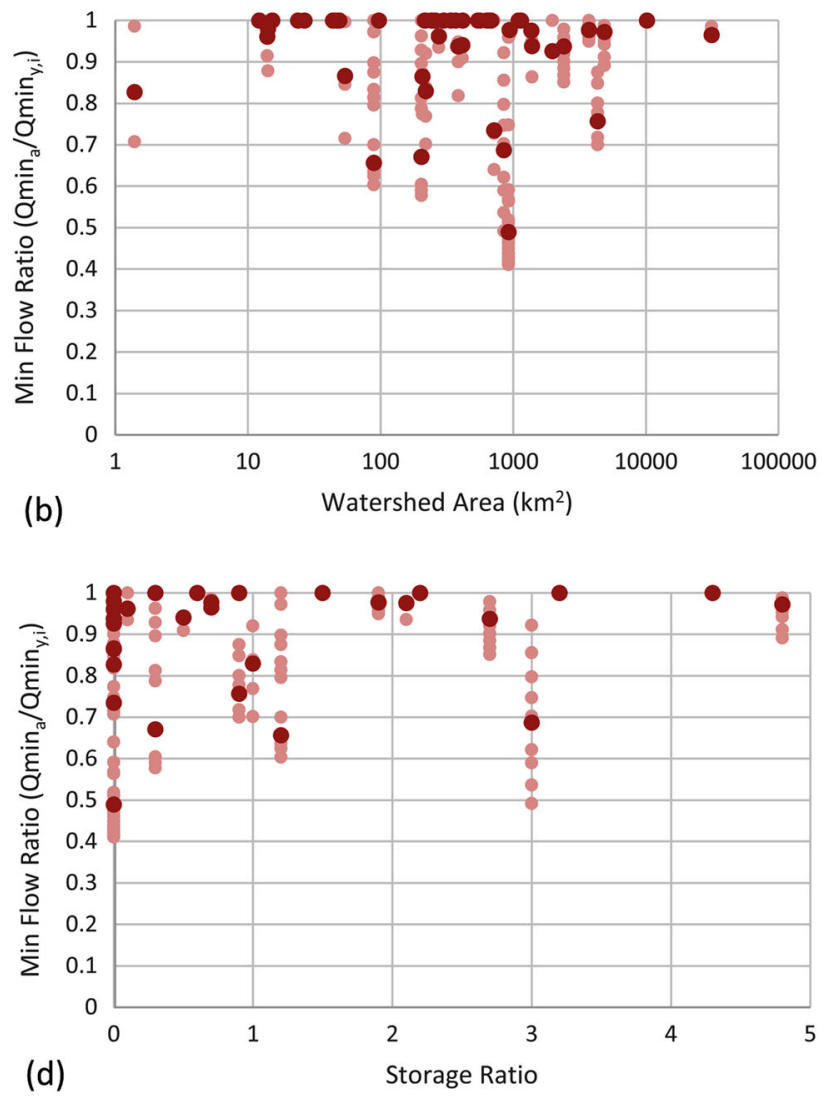

Storage ratio calculated as the upstream usable reservoir storage divided by the mean annual runoff for the study period. Data shown for daily subsample interval only

only. The dark red points are average values for each of the 50 sites. The light red points show the 50 iterations for each of the 50 sites. Table 3 shows Pearson's $r$ values between average flow ratios (i.e., one value per site; total of 50) and (1) latitude, (2) watershed area, (3) R-B Index, and (4) storage ratio. Pearson's $r$ values were tested for significance with a two-tailed $p$-value hypothesis test $(n=50, p=0.05$; Table 3); statistically significant values are shown with bold and italic font (i.e., Pearson's $r>0.28$ ). Values shown in dark red had mathematical dependencies between variables (see note under Table 3); therefore, significance tests are non-valid, so values have regular font styles.

There were statistically significant correlations between subsampled average minimum flow ratios and latitude and R-B Index; no significant correlations were seen with watershed area and Storage Ratio (Table 3 and Fig. 10). In general, this indicated that minimum flow estimates became more accurate as latitude decreased and as flashiness increased. The strength of the statistically significant correlations increased as subsample frequency decreased.

There were statistically significant correlations between subsampled average maximum flow ratios and latitude, 
Table 3 Pearson's $r$ values (i.e., correlation coefficients) between average flow ratios and (1) latitude (decimal degrees), (2) watershed area $\left(\mathrm{km}^{2}\right)$, (3) R-B index (unitless), and (4) storage ratio (unitless)

\begin{tabular}{|c|c|c|c|c|c|}
\hline Ratio & Subsample Interval & Latitude & Watershed Area & R-B Index ${ }^{a}$ & Storage Ratio $^{a}$ \\
\hline & Daily & -0.36 & 0.03 & 0.33 & -0.01 \\
\hline Min Flow & Three Day & -0.37 & 0.04 & 0.36 & -0.02 \\
\hline \multirow[t]{3}{*}{ Ratio } & Weekly & -0.37 & 0.04 & 0.37 & -0.06 \\
\hline & Monthly & -0.42 & 0.01 & 0.41 & -0.08 \\
\hline & Daily & 0.47 & 0.41 & -0.58 & 0.43 \\
\hline \multirow{4}{*}{$\begin{array}{c}\text { Max Flow } \\
\text { Ratio }\end{array}$} & Three Day & 0.42 & 0.49 & -0.59 & 0.53 \\
\hline & Weekly & 0.37 & 0.52 & -0.62 & 0.54 \\
\hline & Monthly & 0.30 & 0.55 & -0.62 & 0.54 \\
\hline & Daily & -0.51 & -0.21 & 0.90 & -0.30 \\
\hline \multirow{3}{*}{$\begin{array}{l}\text { Runoff } \\
\text { Ratio * }\end{array}$} & Three Day & -0.49 & -0.21 & 0.92 & -0.28 \\
\hline & Weekly & -0.49 & -0.23 & 0.91 & -0.28 \\
\hline & Monthly & -0.52 & -0.26 & 0.93 & -0.20 \\
\hline
\end{tabular}

Data used from all 50 sites for all four subsample intervals. Statistically significant (two tailed; $p=0.05$ ) Pearson's $r$ values shown in bold italic font

${ }^{a}$ Values shown in dark red have mathematical dependencies between variables; Runoff Ratio, R-B Index, and Storage ratio are each normalized by runoff. Therefore, dark red values cannot be compared to light red values, but can be compared in a relative sense to other dark red values. Note that statistical significance is also impacted by this dependency

watershed area, R-B Index, and storage ratio (Table 3 and Fig. 11). In general, this indicated that maximum flow estimates became more accurate as latitude, watershed area, and storage ratio increased, and R-B index decreased. The strength of the watershed area, R-B index and storage ratio correlations increased as subsample frequency decreased. In contrast, the strength of the correlation with latitude decreased as subsample frequency decreased.

There were statistically significant correlations between subsampled average runoff ratio and latitude (Table 3 and Fig. 12; see note below Table 3). In general, this indicated that runoff estimates became more accurate as latitude increased. The strength of this correlations was relatively unaffected by decreased subsample frequency.

\section{Discussion}

Accurate streamflow statistics of minimum flow, maximum flow, and runoff often form the basis of sound water resource management and planning. Assuming (1) subsampled water level observations are as precise and accurate as continuous observations and (2) an equally accurate stage-discharge curve is available for converting observed water levels to flows, this analysis indicates that lower frequency observations of stream stage and flow can be useful, and could play a role in hydrologic data generation. The utility of lower frequency data depends largely on what the ultimate use(s) of the data are. Table 4 provides a summary of the discussion organized by the hypotheses presented in Table 1.

One limitation of our approach was the assumption that citizen science spot measurements of water level or stage could be converted to flow with the same accuracy as 15-min continuous USGS records. Much of the challenge of streamflow monitoring lies precisely in the conversion from stage to flow, or the development of the stage-discharge rating curve (Braca 2008). For example, many of the USGS rating curves implicitly utilized in this analysis were developed by trained hydrometric professionals using sophisticated and expensive equipment over the course of several decades. In addition to uncertainties in water level observations, the discussion about Citizen Hydrology should also focus on understanding uncertainties in rating curves (Mason et al. 2016; McMillan and Westerberg 2015; Domeneghetti et al. 2012 and others), focusing on those developed from infrequent observations, or on new methods for Citizen Hydrologists to accurately observe streamflow directly. The associated uncertainties with these new methods will need to be assessed to capture the comprehensive uncertainties of Citizen Hydrology data.

\section{Minimum Flow}

Estimates of minimum flow discussed in section Minimum flow results, as compared to maximum flow and runoff (sections Maximum flow results and Runoff results, respectively), were the least sensitive to changes in 

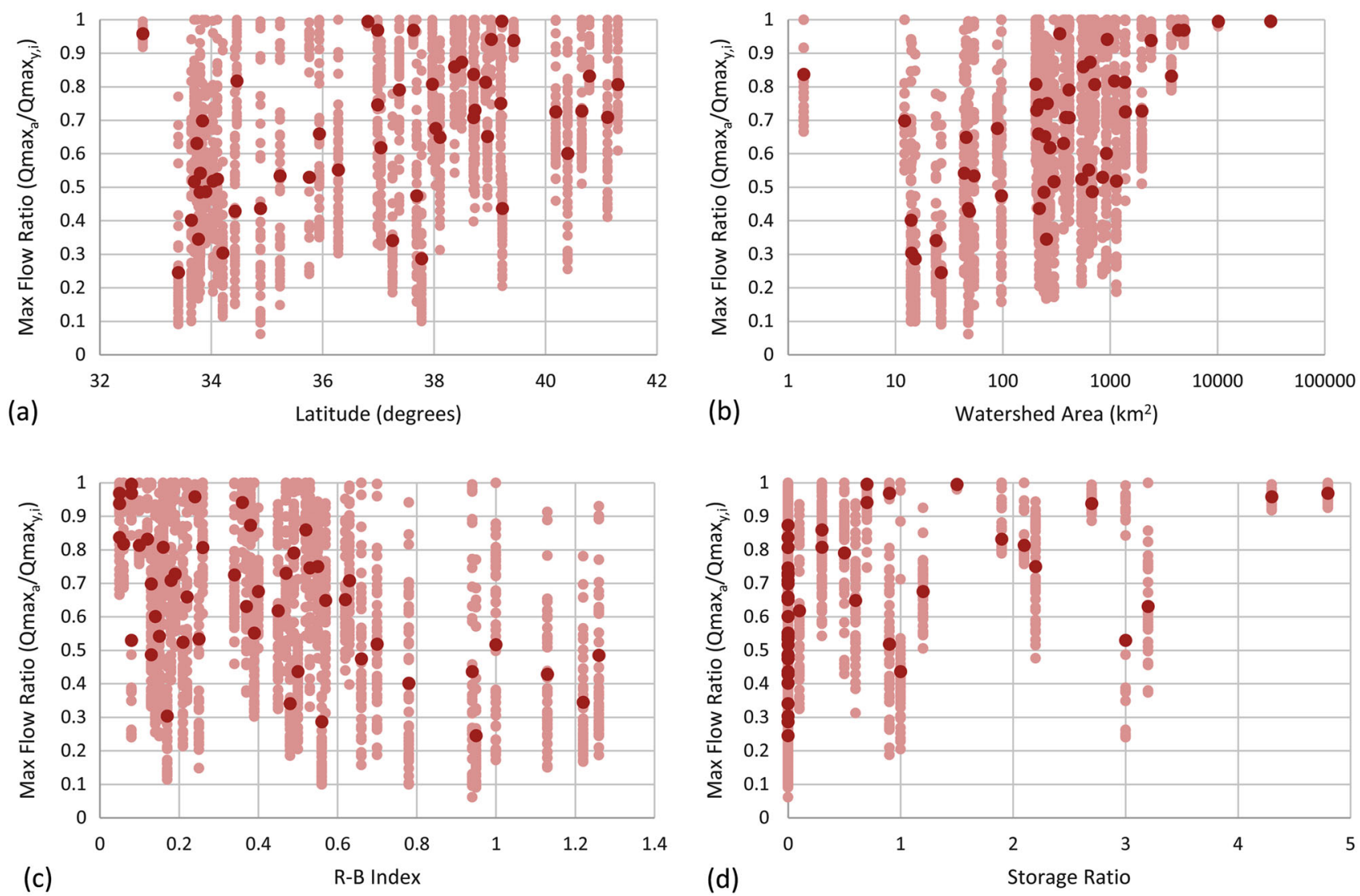

Fig. 11 Scatter plots of maximum flow ratio as a function of a latitude (decimal degrees), b watershed area $\left(\mathrm{km}^{2}\right)$, c Richards-Baker flashiness index (R-B index), and $\mathbf{d}$ storage ratio. Average data for all 50 sites shown in dark red; data for all 50 iterations shown in light red.

Storage ratio calculated as the upstream usable reservoir storage divided by the mean annual runoff for the study period. Data shown for daily subsample interval only

subsample intervals. Because minimum flows tend to persist for longer timescales, they were estimated within $10 \%$ for half of the subsample iterations at 39 (daily) and 23 (monthly) of the 50 sites. There were statistically significant correlations between subsampled average minimum flow ratios and latitude and R-B Index. Precipitation in California has a positive correlation with latitude. We suggest that the observed negative correlation between latitude was due to north-to-south trends in precipitation, resulting in fewer ephemeral streams and more variable minimum flows as latitude increases. Subsampled measurements are most likely to characterize minimum flows for ephemeral streams, or streams that normally go dry for at least certain parts of the year. Streams that run dry also typically have a higher flashiness index.

\section{Maximum Flow}

Because maximum flows occur only briefly, it is unlikely that reliable maximum flow estimates (section Maximum flow results) will be obtained from subsampled measurements with average observation intervals of daily or greater.

For example, maximum flows were estimated within $10 \%$ for half of the subsample iterations at only 7 (daily) and 0 (monthly) sites. This is consistent with Cheviron et al. (2014) who found that only observation intervals that are smaller than the characteristic time period of fluctuations in the variable of interest tend to ensure reliable approximations. Therefore, if the primary monitoring objective is developing data for water resources infrastructure design, whereby maximum flows are required as design criteria, we suggested either (1) variable observation frequency based Citizen Hydrology (e.g., it is raining so go take measurements; see section Variable observation frequencies) or traditional continuous stream gauging methods. Our results also indicate that a simple mechanical maximum level gauge with a manual reset similar to that discussed by Bragg et al. (1994) could be an important addition to Citizen Hydrology flow monitoring sites if maximum water levels and flows need to be assessed. There were statistically significant correlations between subsampled maximum flow ratios and latitude, watershed area, R-B Index, and storage ratio (Table 3 and Fig. 11). The strongest correlations were between maximum flow ratios and R-B 

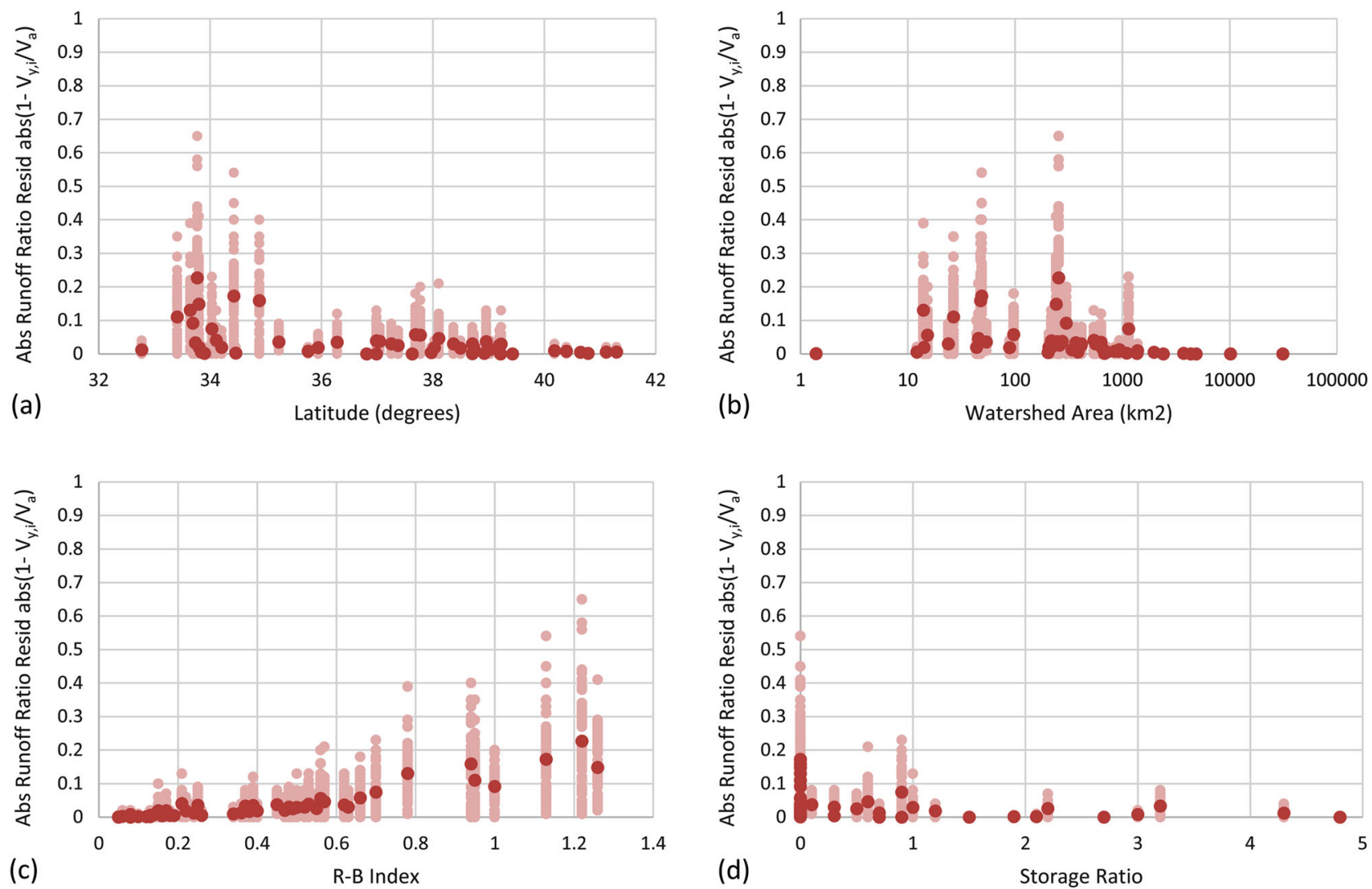

Fig. 12 Scatter plots of the absolute value of the runoff ratio residual (i.e., $1-V_{y, i} / V_{a}$ ) as a function of a latitude (decimal degrees), b watershed area $\left(\mathrm{km}^{2}\right)$, c Richards-Baker flashiness index (R-B Index), and $\mathbf{d}$ storage ratio. Average data for all 50 sites shown in dark

red; data for all 50 iterations shown in light red. Storage ratio calculated as the upstream usable reservoir storage divided by the mean annual runoff for the study period. Data shown for daily subsample interval only

Index, followed closely by storage ratio and watershed area. One of the strongest controls on the timescales of the rainfall-runoff relationship is watershed area. All else being equal, larger watersheds have more temporally damped runoff responses, and vice versa. Additionally, significant reservoir water storage (i.e., high storage ratio) can drastically affect stream hydrographs, with one of the significant impacts being a "flattening" of the hydrograph (Vörösmarty and Sahagian 2000). This "flattening" of the hydrograph increases chances of characterizing maximum flows with lower frequency observations, especially as observation frequency decreases. Therefore, these results were congruent with our intuitions, and are similar to those discussed by Horowitz et al. (2015).

\section{Runoff}

Runoff volumes were estimated within $10 \%$ for half of the iterations at 44 (daily) and 12 (monthly) of the 50 sites. The systematic negative bias in runoff estimates that increased as the subsample frequency decreased is congruent with the

findings of Coynel et al. (2004). Data assimilation could be helpful to correct for these biases (see section Data assimilation). For daily observations on streams with average flows greater than $0.2 \mathrm{~m}^{3} \mathrm{~s}^{-1}$, or storage ratios greater than one, runoff was estimated within $20 \%$ (except for one site) and $10 \%$, respectively for half of the subsample iterations. There were statistically significant correlations between subsampled runoff residuals and latitude and watershed area (Table 3 and Fig. 12). There are mathematical dependencies between runoff ratio and R-B Index and storage ratio, because each are normalized by runoff. Therefore, Pearson's $r$ for these relationships should not be directly compared to other Pearson's $r$ values. Additionally, statistical significance is also impacted by this dependency. Since runoff residuals closer to zero indicate more accurate characterizations of runoff, negative correlations with latitude, watershed area, and storage ratio suggest runoff estimates improve as these variables increase. Congruent with intuition, the positive correlation between runoff ratio and R-B Index indicates that runoff can be more accurately estimated from low frequency observations in watersheds with low 


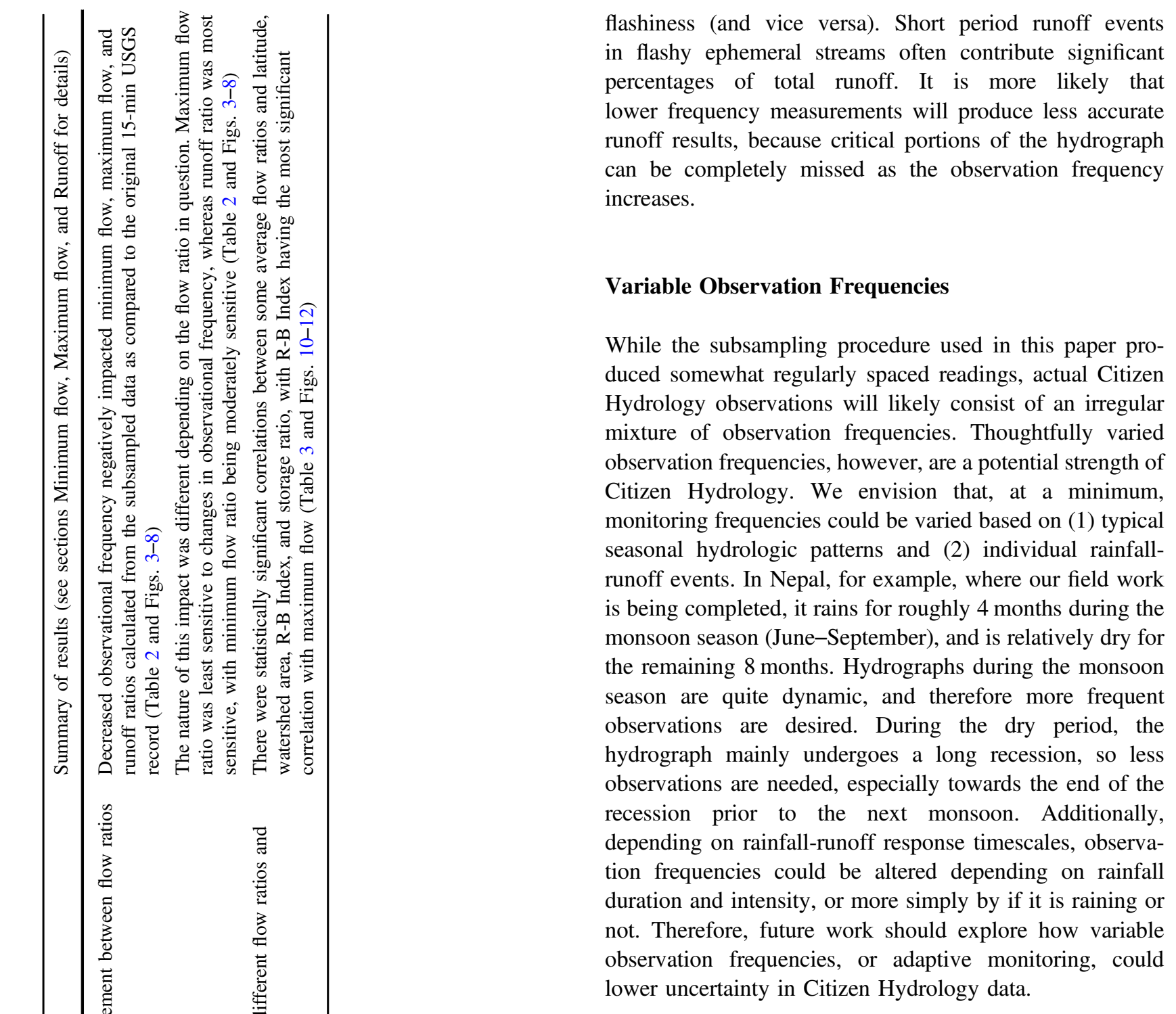

\section{Data Assimilation}

We suggest that data assimilation (briefly mentioned in section Runoff), or a systematic combination of modeling and observations, could be promising methodology for adding value to, and improving accuracy of, Citizen Hydrology observations. For example, higher frequency observations of rainfall collected by a permanently installed sensor could be combined with lower frequency observations of stream stage and flow performed by Citizen Hydrologists. Then, in the context of a rainfall-runoff model, these data could be combined to help "fill in the gaps" of the hydrograph. Data assimilation has the possibility to improve minimum flow, maximum flow, and runoff estimates based on lower frequency observations, and should be the focus of future Citizen Hydrology research. 


\section{Relevance for Data Poor Regions}

The results of this research are most meaningful if the watersheds chosen for subsampling from the "data rich" region(s) are similar to those of the "data poor" region(s) targeted for applications of Citizen Hydrology. For our purpose of designing a Citizen Hydrology monitoring campaign in Nepal, we specifically chose stream gauges from California for subsampling because of (1) the abundance of high quality stream gauging stations and (2) the topographic and climate similarities with Nepal. For example, both California and Nepal have well-defined 4 to 5 month long wet periods when the majority of precipitation occurs (i.e., November-March and June-September, respectively), followed by prolonged dry periods. During the wet periods, both California and Nepal have significant precipitation events that occur due to the strong winter Pacific jet stream (Dettinger et al. 2011) and the Asian Summer Monsoon (Ramage 1971), respectively. Additionally, both California and Nepal have significant topographic variations in a direction perpendicular to the predominant direction of the jet stream. In the case of California, low pressure systems from the Pacific Ocean typically move to the east, and are forced over the Sierra Nevada mountains, which predominantly run north to south. In Nepal, the South Asian monsoon moves to the north, while the Himalayas predominantly run east to west. While results from this analysis can be used to inform Citizen Hydrology efforts in "data poor" regions with dissimilar hydrologic contexts to that of California, it is suggested that the subsampling procedures discussed herein be repeated for hydrologically similar "data rich" regions.

As a sample "data poor" region application, we are using Citizen Hydrology observations to estimate runoff in several sub-watersheds $\left(10-587 \mathrm{~km}^{2}\right)$ of the Bagmati River watershed in the Kathmandu Valley. Precipitation patterns and amounts for the Kathmandu Valley are similar to those in Northern California (i.e., above a latitude of roughly 36 north). There are 31 watersheds with a latitude above 36 included in this study ranging in size from 1 to $31,313 \mathrm{~km}^{2}$. The highest R-B Index observed for these 31 sites was 0.66 for SiteID 11181000. For daily observation frequencies, out of a total of 1550 site-subsamples (i.e. 31 sites times 50 subsamples), only 28 site-subsamples had runoff errors greater than $10 \%$, and only one site-subsample exceeded $20 \%$; the average runoff error was $1.9 \%$. With the assumptions previously stated at the end of the section Background and introduction in mind (i.e. regarding water level observation accuracy and stage-discharge curve availability), these results give us reasonable confidence that runoff estimates based on daily Citizen Hydrology observations should be within $10 \%$ of actual runoff, if not better.

\section{Summary and Conclusions}

The goal of this paper was to investigate the impacts of lower frequency observations (i.e., daily, three day, weekly, and monthly), similar to those that could be produced by Citizen Hydrology, on the accuracy of basic streamflow statistics like minimum flow, maximum flow, and runoff. To answer this question, we performed a subsampling analysis on 7 years of streamflow data from 50 USGS gauging stations in California. Depending on the questions being asked, and the characteristics of the watershed(s) in question, lower frequency observations, such as those produced from Citizen Hydrology, can provide useful hydrologic information. In general, as watershed flashiness decreases and storage ratio increases, the reliability of minimum flow, maximum flow, and runoff estimates obtained from low frequency observations increases. Also, as latitude increases, which for California is a reasonable proxy for precipitation, the reliability of runoff estimates based on low frequency observations increases. Interestingly, watershed size seems to play a less prominent role than latitude (i.e., precipitation), R-B Index, and storage ratio in determining reliability of low frequency observation based runoff estimates.

Acknowledgements In-kind support for this work was provided by Delft University of Technology, SmartPhones4Water, and California State University, Chico. A special thank you to Steffen Mehl and James Norris at California State University, Chico for their help getting these ideas off the ground. The helpful comments provided by two anonymous reviewers and the Associate Editor, Angus Webb, added significant value to the paper and are also appreciated.

\section{Compliance with Ethical Standards}

Conflict of Interest The authors declare that they have no competing interests.

Open Access This article is distributed under the terms of the Creative Commons Attribution 4.0 International License (http://crea tivecommons.org/licenses/by/4.0/), which permits unrestricted use, distribution, and reproduction in any medium, provided you give appropriate credit to the original author(s) and the source, provide a link to the Creative Commons license, and indicate if changes were made.

\section{References}

Anokwa Y, Hartung C, Brunette W (2009) Open source data collection in the developing world. Computer 42(10):97-99. http://doi. ieeecomputersociety.org/10.1109/MC.2009.328

Baker DB, Richards RP, Loftus TT, Kramer JW (2004) A new flashiness index: characteristics and applications to midwestern rivers and streams. J Am Water Res Assoc 40(2):503-522. doi:10.1111/j.1752-1688.2004.tb01046.x

Braca G, (2008), Stage-discharge relationships in open channels: practices and problems, FORALPS Technical Report, 11. 
Università degli Studi di Trento, Dipartimento di Ingegneria Civile e Ambientale, Trento, p 24

Bragg OM, Hulme PD, Ingram HAP, Johnston JP (1994) A maximum-minimum recorder for shallow water tables, developed for ecohydrological studies on mires. J Appl Ecol 31(3):589

Buytaert W, Zulkafli Z, Grainger S, Acosta L, Alemie TC, Bastiaensen J, eBièvre B, Bhusal J, Clark J, Dewulf A, Foggin M, Hannah DM, Hergarten C, Isaeva A, Karpouzoglou T, Pandeya B, Paudel D, Sharma K, Steenhuis T, Tilahun S, VanHecken G, Zhumanova M (2014) Citizen science in hydrology and water resources: opportunities for knowledge generation, ecosystem service management, and sustainable development. Front Earth Sci 2:26. doi:10.3389/feart.2014.00026

Cheviron B, Delmas M, Cerdan O, Mouchel J-M (2014) Calculation of river sediment fluxes from uncertain and infrequent measurements. J Hydrol 508:364-373

Coynel A, Schäfer J, Hurtrez JE, Dumas J, Etcheber H, Blanc G (2004) Sampling frequency and accuracy of SPM flux estimates in two contrasted drainage basins. Sci Total Environ 330 (1):233-247. doi:10.1016/j.scitotenv.2004.04.003

Dettinger MD, Ralph FM, Das T, Neiman PJ, Cayan DR (2011) Atmospheric rivers, floods and the water resources of California. Water 2011(3):445-478

Domeneghetti A, Castellarin A, Brath A (2012) Assessing rating-curve uncertainty and its effects on hydraulic model calibration. Hydrol Earth Syst Sci 16(4):1191-1202. doi:10.5194/hess-161191-2012

Efron B, Tibshirani RJ (1993) An introduction to the bootstrap. Chapman \& Hall, New York, ISBN 0-412-04231-2

Fienen MN, Lowry CS (2012) Social. Water-a crowdsourcing tool for environmental data acquisition. Comput Geosci 49:164-169. doi:10.1016/j.cageo.2012.06.015

Gleick PH (1998) Water in crisis: paths to sustainable water use. Ecol Appl 8:571-579. doi:10.1890/1051-0761(1998)008[0571:WICPTS] 2.0.CO;2

Hannah DM, Demuth S, van Lanen HAJ, Looser U, Prudhomme C, Rees $\mathrm{G}$ et al. (2011) Large-scale river flow archives: importance, current status and future needs. Hydrol Process 25:1191-1200. doi:10.1002/hyp.7794

Hirsch RM, Costa JE (2004) U.S. stream flow measurement and data dissemination improve. Eos Trans AGU 85(20):197-203. doi:10. 1029/2004EO200002

Horowitz AJ, Clarke RT, Merten GH (2015) The effects of sample scheduling and sample numbers on estimates of the annual fluxes of suspended sediment in fluvial systems. Hydrol Process 29 (4):531-543. doi:10.1002/hyp.10172

Jones AS, Horsburgh JS, Mesner NO, Ryel RJ, Stevens DK (2012) Influence of sampling frequency on estimation of annual total phosphorus and total suspended solids loads. JAWRA J Am Water Resour Assoc 48:1258-1275. doi:10.1111/j.1752-1688.2012.00684

Keough HL, Blahna DJ (2006) Achieving integrative, collaborative ecosystem management. Conserv Biol 20:1373-1382. doi:10. 1111/j.1523-1739.2006.00445.x

Kruger LE, Shannon MA (2000) Getting to know ourselves and our places through participation in civic social assessment. Soc Nat Resour 13:461-478. doi:10.1080/089419200403866

Mason Jr RR, Kiang JE, Cohn TA (2016) Rating curve uncertainty. River Flow, CRC Press, p 729-734.

Mazzoleni M, Verlaan M, Alfonso L, Monego M, Norbiato D, Ferri M, Solomatine DP (2015) Can assimilation of crowdsourced streamflow observations in hydrological modelling improve flood prediction? Hydrol Earth Syst Sci Discuss 12:11371-11419. doi:10.5194/hessd-12-11371-2015. www.hydrol-earth-syst-scidiscuss.net/12/11371/2015/

McMillan HK, Westerberg IK (2015) Rating curve estimation under epistemic uncertainty. Hydrol Process 29(7):1873-1882. doi:10. 1002/hyp.10419

Mishra AK, Coulibaly P (2009) Developments in hydrometric network design: a review. Rev Geophys 47:RG2001. doi:10.1029/ 2007RG000243

Moss ME, Tasker GD (1991) An intercomparison of hydrological network design technologies. Hydrol Sci J 36(3):209-221. doi:10.1080/02626669109492504

Nagendra H, Karmacharya M, Karna B (2005) Evaluating forest management in Nepal: views across space and time. Ecol Soc 10 (1):24, http://www.ecologyandsociety.org/vol10/iss 1/art24/

O'Grady $\mathrm{M}$ et al. (2016) Intelligent sensing for citizen sciencechallenges and future directions. Mob Netw Appl 21:375. doi:10. 1007/s11036-016-0682-z

Pearson C (1998) Changes to New Zealand's national hydrometric network in the 1990's. N Z J Hydrol 37:1-17

Python v2.7 (2016) Python Software Foundation, Python Language Reference, version 2.7. http://www.python.org

Ramage CS (1971) Monsoon meteorology, international geophysics series. Academic Press, New York

Sanz SF, Holocher-Ertl T, Kieslinger B, Sanz F, und Candida G and Silva G (2014), White Paper on Citizen Science in Europe, Socientize Consortium. http://www.zsi.at/object/project/2340/atta ch/White_Paper-Final-Print.pdf

Savan B, Morgan A, Gore C (2003) Volunteer environmental monitoring and the role of the universities: the case of citizen's watch. Environ Manage 31:561-568

Shrestha S, Pradhananga D, Pandey VP (2012) Kathmandu valley groundwater outlook, Asian Institute of Technology (AIT), The Small Earth Nepal (SEN), Center of Research for Environment Energy and Water (CREEW), International Research Center for River Basin Environment-University of Yamanashi (ICRE-UY), Kathmandu, Nepal

Sultana P, Abeyasekera S (2008) Effectiveness of participatory planning for community management of fisheries in Bangladesh. J Environ Manage 86:201-213

Thoreson BP, Eckhardt J, Divine AJ (1999) Correlation between sampling interval and daily volume calculations, in benchmarking irrigation system performance using water measurement and water balances. Proceedings from the USCID Water Management Seminar, San Luis Obispo, CA. pp 121-134

Turnipseed DP, Sauer VB (2010), Discharge measurements at gaging stations: U.S. geological survey techniques and methods book 3 , chap. A8. p 87. http://pubs.usgs.gov/tm/tm3-a8/

van de Giesen N, Hut R, Selker J (2014) The Trans-African hydrometeorological observatory (TAHMO). Wiley Interdiscip Rev 1:341-348. doi:10.1002/wat2.1034

van Overloop PJ, Davids JC, and Vierstra MM (2014), Mobile monitoring technologies: the mobiletracker and the remotetracker. Proceedings of USCID Conference, Sacramento, California

Vörösmarty CJ, Sahagian D (2000) Anthropogenic disturbance of the terrestrial water cycle. BioScience 50(9):753-765

Whitelaw G, Vaughan H, Craig B, Atkinson D (2003) Establishing the Canadian community monitoring network. Environ Monit Assess 88:409-418. doi:10.1023/A:1025545813057 